\title{
Thermodynamic simulation of a micro advanced adiabatic compressed air energy storage for building application
}

\author{
Ghady Dib ${ }^{12^{*}}$, Philippe Haberschill ${ }^{1}$, Romuald Rulliere ${ }^{1}$, Quentin Perroit ${ }^{2}$, \\ Simon Davies ${ }^{2}$, Rémi Revellin ${ }^{1}$
}

${ }^{1}$ Univ Lyon, CNRS, INSA-Lyon, Université Claude Bernard Lyon 1, CETHIL UMR5008 Villeurbanne, 69621 France

${ }^{2}$ AIA Life Designers - AIA environnement 20, rue Lortet - 69007 Lyon, France

*(Ghady Dib: ghady.dib@insa-lyon.fr)

\begin{abstract}
In the context of developing renewable energies, storing energy improves energy efficiency and promotes the insertion of intermittent renewable energies. It consists of accumulating energy for later use in a place that may be the same or different from the place of production. Converting electrical energy to high-pressure air seems a promising solution in the energy storage field: it is characterized by a high reliability, low environmental impact and a remarkable energy density. This article carries out a novel numerical global model of micro advanced adiabatic compressed air energy storage based on thermodynamic and energy analysis of components available commercially in the market: photovoltaic panels coupled to building model and storage system. This model allows to study multiple sizing parameters (solar surface, storage volume, geographical locations, compression/expansion ratio) based on energy production (renewable energy, grid) and energy storage technology. The results show an interesting energy part of $64 \%$ that answered the total building electric energy consumption based on solar production and energy resulted from storage. Levelized cost of energy analysis is also provided to highlight the influence of the critical parameter in the context of developing a micro compressed air energy storage system based on commercial units available in the market.
\end{abstract}

Keywords: Energy storage, advanced adiabatic, compression/expansion, numerical model, energy building demand 


\section{Nomenclature}

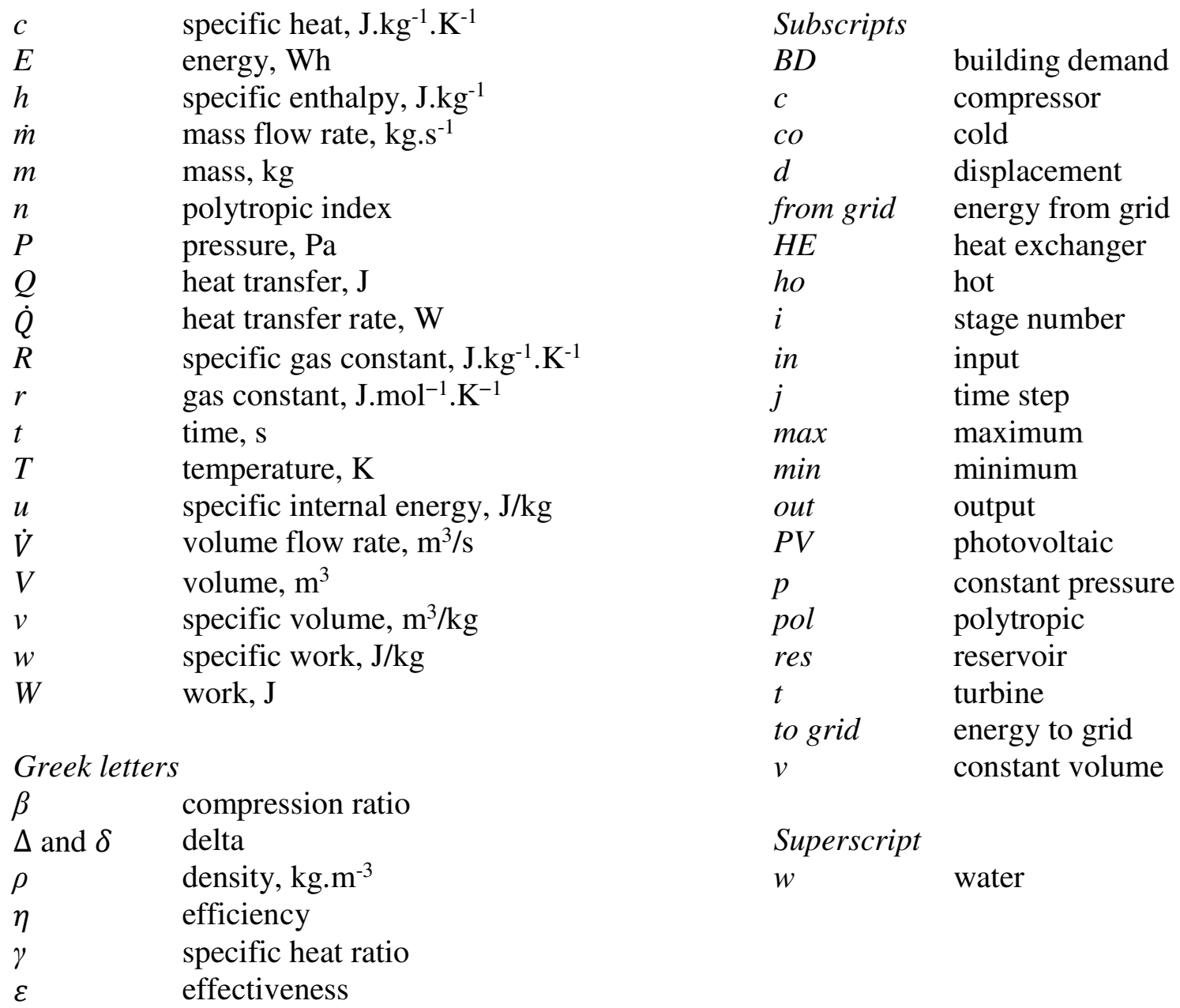

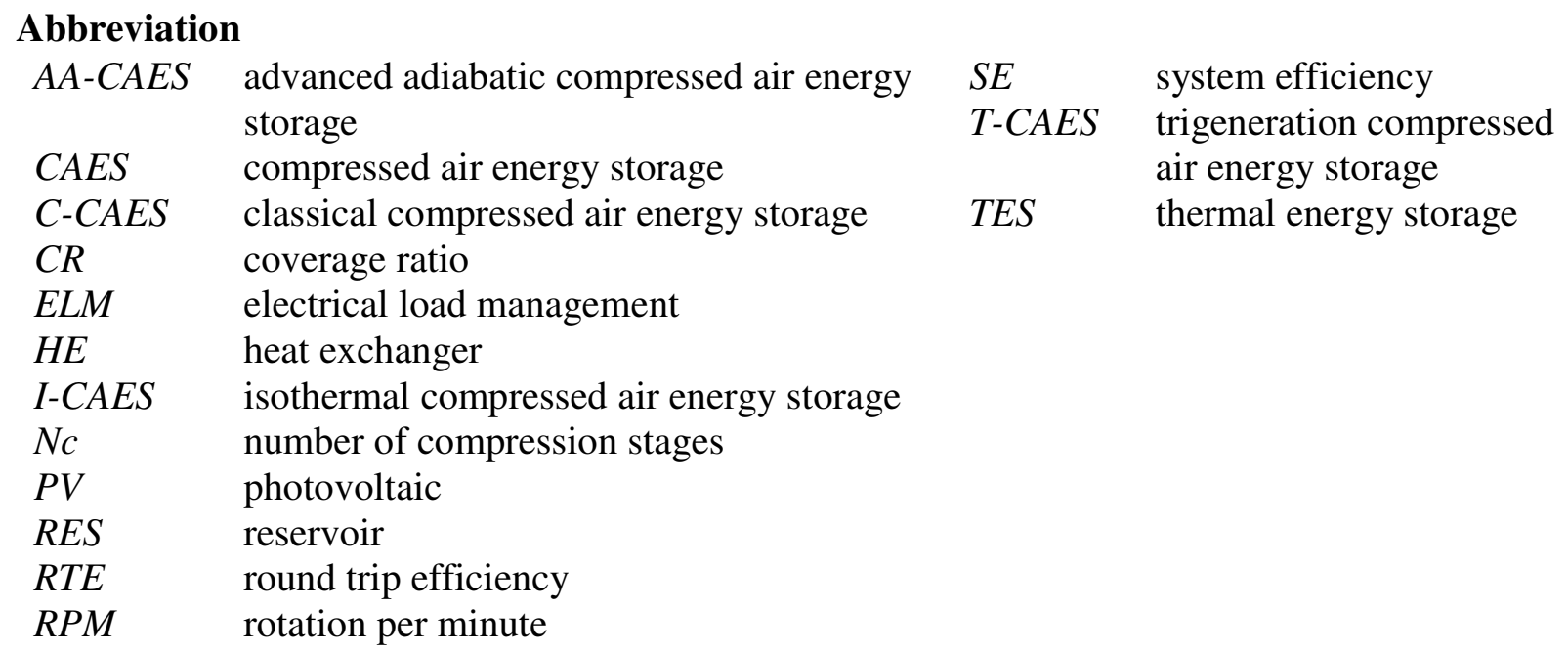




\section{Introduction}

\subsection{World energy outlook}

The spectacular growth of the world population during the $21^{\text {st }}$ century, the industrial development and the rapid urbanization are reflecting a significant increase in the world energy demand. Based on the world energy outlook 2018 by the international energy agency, the global energy demand will rise more than $25 \%$ by 2040 [1]. With government policies and decisions, the renewable energy has become the technology of choice in order to ensure sustainable clean energy and reduce carbon emissions. This fact can justify the expected growth of the renewable share by one-fifth to reach $12.4 \%$ in responding to global energy demand in 2023 [1-3]. Renewable resources intermittency presents a major obstacle and challenge in ensuring a constant answer especially to high energy demands. The energy storage technology can be a solution for the energy fluctuating issues and thus stabilizing the grid by allowing excess energy production to be saved for periods of higher customer demand [4]. In 2017, the share of the world renewable electricity generation was $24 \%$ where hydropower-hydraulic storage technology (STEP) presented the important part $(75 \%)$ and the rest of electricity demand was answered through the import of electricity and the use of gas, fuel and coal conventional power plants [2].

\subsection{Energy storage technologies}

The deployment of other storage systems with low environmental impact can help to lower the cost of imported electricity and significantly reduce the $\mathrm{CO}_{2}$ emissions generated by the use of thermal power plants and the dependence on fossil resources [5]. The "French Alternative Energies and Atomic Energy Commission" (CEA) [5] and Luo et al. [6] detailed different energy storage technologies that provide flexibility and enhance the reliability of energy systems (Flywheel, batteries, thermal storage, supercapacitors, hydrogen storage and compressed air energy storage). Each technology depending on its application presents several technical and economic reasons that limit certain of its advantages [6,7]. However, the compressed air energy storage system (CAES) is one of the most promising technologies in the field of smart grid and poly-generation system in the near future $[4,7,8,9]$. CAES presents several significant advantages due to its cleanliness, reliability, economic feasibility, long service life and low environmental impact $[4,9]$. Venkataramani et al. [4] concluded that the integration of CAES with renewable resources, such as solar and wind, will improve the utilization of these resources through demand side management 
toward increasing renewable power recovery. According to CEA, CAES technology presents between the lowest investment cost per power and energy unit ( $€ / \mathrm{kW}$, $€ / \mathrm{kWh})$ compared to Li-ion batteries and STEP energy storage technology [5].

\subsection{Classical CAES (C-CAES)}

There have been in existence two conventional CAES plants in the world running more than 20 years [10]; Huntorf in Germany (built in 1978) with a capacity of 290 MW and the AEC plant in the United States (built in 1991) with a capacity of 110 MW [11], and with an electric efficiency (electrical energy output divided by electrical energy input) of $46 \%$ and $54 \%$ respectively. In these classical compressed air energy storage plants (C-CAES) air is compressed adiabatically and stored in former salt cavities or coal mines. Heat resulting from compression phase is wasted to the ambient. External heat source combustion is used to raise the air temperature before entering the turbine for adiabatic expansion [12].

\subsection{Advanced Adiabatic CAES (AA-CAES)}

CAES systems allow an electrical efficiency ranging from 40 to $70 \%$ depending on the heat/cold management resulting from air compression/expansion [13]. Thus, if the heat of compression and cold of expansion are stored separately for reuse respectively during air expansion and compression, the storage system is said advanced adiabatic (AA-CAES) and its electrical efficiency can reach up to $70 \%$ according to INERIS [14].

\subsection{Isothermal CAES (I-CAES)}

Isothermal compressed air energy storage (I-CAES) is an emerging technology where isothermal compression/expansion are applied. Heat is removed continuously during the air compression cycle and added continuously during the air expansion cycle. This will result in collecting the cold at the end of the expansion phase that will be added to the next air compression cycle. In fact, it allows to reduce the compensated work during the air compression and to increase the work recovered during the air expansion. Two important innovative technologies are currently developed: mechanical piston with water injection by LighSail Energy [15] and liquid piston with integrated heat exchanger by Enairys [16].

1.6. Micro Advanced Adiabatic CAES (Micro AA-CAES) 
While most large-scale (>50 MW) CAES systems depend on various geological factors (underground storage) that are difficult to control for air storage, micro-CAES systems $(<1 \mathrm{MW})$ with specifically developed air tanks may be more adaptable and effective solutions in meeting the electricity, heat and cold needs [9]. Many researchers have focused on the micro AA-CAES system.

\subsubsection{Sizing different system configurations}

Kim et al. [17] studied the energy and exergy analysis of eight different system configurations for achieving high efficiencies. They found that a micro AA-CAES system with heat recovery is a very effective system for distributed power networks because it can be a combination of energy storage, generation, air-cycle, heating and cooling system and it has a good efficiency (about 60 $\%)$. Xue et al. [18] developed thermodynamic and economic models for hybrid AA-CAES system combining solid and liquid TES (thermal energy storage). The hybrid system presented a lower cost for a given efficiency. A modified model for the AA-CAES structure was conducted by Liu et al. [19]. They reported an improvement of the exergy efficiency by $3 \%$ due to the reuse of the discharged air where its temperature is still high. Chen et al. [20] developed a mathematical model based on thermodynamic laws that shows an improvement of $3 \%$ of the roundtrip efficiency (RTE) compared to C-CAES by pre-cooling the air entering the compressor. Hartman et al. [21] found that the efficiency of the polytropic configuration is more realistic (60\%) than the adiabatic system $(70 \%)$. These differences in system efficiency depend on many design parameters and assumptions used in specific studies based on steady thermodynamic models. Zhang et al. [22] stated that air reservoir modeling is an important AA-CAES design factor. Based on their study, a constant volume and temperature reservoir model has the highest system efficiency. The air storage temperature and pressure influence on RTE was pointed out by Guo et al. [23] where they developed a dynamic compressed air storage model. An optimal after-valve-throttle pressure was shown while taking maximum energy density as goal with constant expander inlet pressure. They added that more heat transfer between the reservoir and the atmosphere results in more stored air in charging and more released air in discharging.

\subsubsection{Trigeneration system studies}

In the literature on micro AA-CAES systems, many scientific papers focused on the design of a trigeneration (T-CAES) system coupled with renewable resources in order to respond to electrical, heating and cooling users demand. Li et al. [24] showed a comprehensive efficiency of 
the storage system ( $~ 50 \%)$ in winter where no cooling power is needed. Jannelli et al. [25] studied the purpose of polygeneration small-scale compressed air energy storage system integrated with photovoltaic power plant of a radio base station for mobile telecommunications where energy storage strategy and cooling energy production are essential. They proposed a novel T-CAES with $57 \%$ of efficiency for a small scale photovoltaic power (3.7 $\mathrm{kW}$ compressor constant input power) plant to satisfy the electric power demand (1.7 $\mathrm{kW}$ expander output power) and to cool the equipment of the radio base station. Li et al. [24] and Jannelli et al. [25] used the same compression/expansion ratio for all the stages. An analytical model based on energy balance and heat transfer equations was developed by Simpore et al. [26] where they simulated micro AACAES system coupled to solar panels and building without heat/cold recovery treatment. Using different energy situation scenarios, the building coverage ratio is higher with the increase of the solar panel area and compressor swept volume. Air tank volume has lower impact in this case. Working at low pressure (15 bar), Lv et al. [27] found the efficiency of T-CAES model to reach $76.3 \%$. Lv et al. worked without air preheating before entering the turbine and supposed that the air charging of the reservoir is an isothermal process.

\subsubsection{Experimental work}

A pilot AA-CAES plant “TICC-500" was proposed by Wang et al. [28] with $22.6 \%$ of RTE. Round trip efficiency is defined as the electrical energy output divided by the electrical energy input. Ambient air is compressed via five intercooled compressors (1375 kWh input electric energy; $315 \mathrm{~kW}$ for 260 minutes of air compression) and released through a regulating valve that keeps the pressure constant at the inlet of three preheated turbines $(326 \mathrm{kWh}$ output electric energy). Cheayb et al. [29] carried out an experimental/numerical approach of a T-CAES composed of three ventilated compression stages driven by $4 \mathrm{~kW}$ motor, $300 \mathrm{~L}$ air reservoir and air motor coupled to a DC generator of $2 \mathrm{~kW}$. Despite the RTE of $15.6 \%$, a good match between the experimental and numerical model was noticed in their work. Heat removed during compression phase is supposed to answer the heating demand and is not reused to preheat the air entering the turbine.

Many researchers presented theoretical and experimental works of different CAES systems trying to stress on the advantage of coupling it with different applications. However, many technological barriers limit the experimental investigations such as high pressure reservoir and high 
inlet pressure turbine. Theoretically speaking, the idea of considering commercial units available in the actual market to develop a micro AA-CAES coupled with photovoltaic power plant to answer building energy needs is missing in the literature mentioned above. In addition, up to our knowledge, a detailed levelized cost analysis of the studied micro AA-CAES system is not found in the literature.

In this study, small scale compressed air energy storage system dedicated to building applications is investigated with the aim of reducing the building sector part (44\%) of the total energy consumption in France that is responsible of 123 millions of tons of $\mathrm{CO}_{2}$ emitted each year [30]. The autonomous global system is achieved by combining renewable energy source and energy storage system with the building. The present paper concentrates on a novel numerical approach based on modeling components that are available in the market on hourly basis for a period of one year. In addition, this global sizing tool offers a wide range of design factor analysis. The studied design factors are: photovoltaic surface, air storage reservoir, heat/cold management, compressor/turbine stages with variable compression/expansion ratio, compressor/turbine displaced volume and rotation per minute (RPM). Furthermore, a new turbine concept is proposed due to non-availability of inlet high pressure turbine in the actual market. In addition, LCOE analysis is proposed in this paper in order to compare the studied storage system integrated into building applications with other storage technologies.

\section{Methodology}

\subsection{System description}

The AA-CAES system configuration proposed in this study is designed in order to satisfy the energy demand of a building model by storing the excess of renewable energy production over a year. Electric energy resulting from the solar energy production is used to power an electric motor that converts it to mechanical energy sufficient to turn on the intercooled compressors. When building energy demand becomes important, compressed air is preheated and introduced to turbines that turn a generator in order to deliver electric energy. Figure 1 shows the main system components that can be presented into four main phases:

- Charge phase: intercooled compressors powered by electric motor are used to compress the ambient air to a fixed reservoir pressure (left upper side). 
- Storage phase: high pressure reservoir model is considered as constant-volume and adiabatic model (middle upper side).

- Discharge phase: compressed air is introduced to a set of heat exchangers and turbines that turn an electrical generator (right upper side).

- TES (thermal energy storage): multiple heat exchangers are used to cool air at the outlet of the compressors and at the same time to preheat the compressed air before entering the turbines (left and right down side). Heat and cold storage are considered an important volume reservoirs so that we have a fixed hot/cold water mass flow and temperature at each inlet of heat exchangers.

The characteristics of the intercooled compressor, air reservoir, heat exchanger and solar panel models are based on commercial units found in the market, while the turbine is based on a hypothetical model in this study.

The building used for this study is modeled and calibrated in another research project "AIR4POWER" that is part of the sustainable production and renewable energy program of ADEME's research, development and innovation (RDI) strategy. In this project, a dynamic thermal simulation was conducted in order to predict the building model energy needs. The building model is composed of different typologies (2908 $\mathrm{m}^{2}$ of office, $1337 \mathrm{~m}^{2}$ of housing, $1971 \mathrm{~m}^{2}$ of hotel, and $597 \mathrm{~m}^{2}$ of commercial space) corresponding to a total surface of $6813 \mathrm{~m}^{2}$. Real occupancy profiles were used (heat generated from one person is estimated to $115 \mathrm{~W} /$ occupant: $70 \mathrm{~W}$ sensible heat and $45 \mathrm{~W}$ latent heat). In addition to the power consumption of household appliances data provided by the CSTB (Scientific and Technical Center for Building).

\section{CAES module}

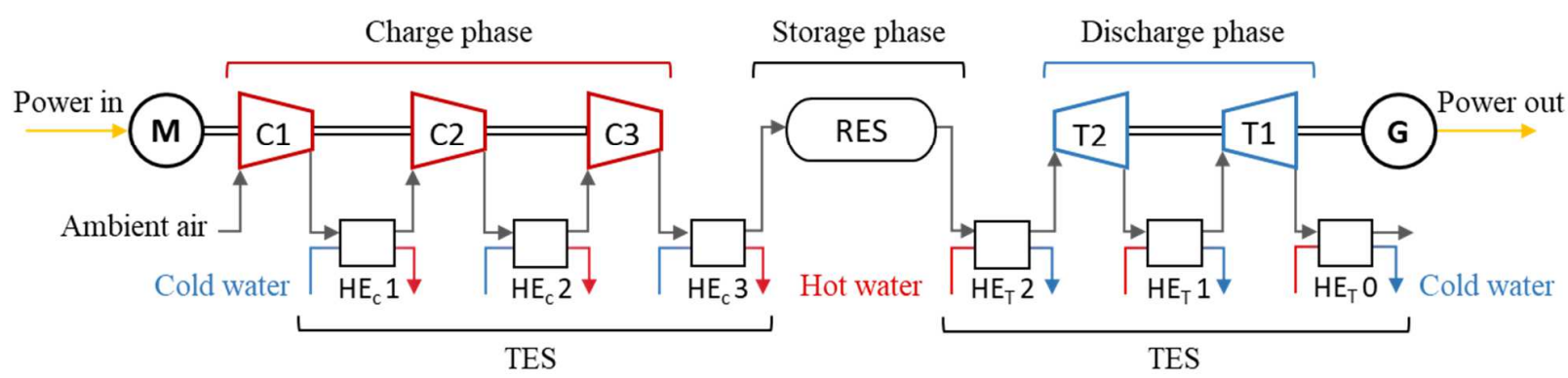

Figure 1: Adiabatic compressed air energy system configuration (for example: 3 compressors and 2 turbines) 


\subsection{Thermodynamic analysis}

\subsubsection{Model assumptions}

The design of the AA-CAES system is based on an analytical analysis for each component of the system. In order to simulate the global system on hourly basis for a period of one year (PV + AA-CAES + Building), a numerical code was developed in Excel VBA that is based on iterative approach. The assumptions taken into consideration in this work are:

- Air is considered as ideal gas.

- Maximum and minimum reservoir pressure are fixed $\left(P_{\max }, P_{\min }\right)$.

- High pressure reservoir is considered as constant volume and adiabatic.

- Cylinder piston volumetric compressor/turbine are considered in this system.

- Displacement volume for the first stage of compressor and turbine are fixed.

- Compressors and turbines are mounted on the same crankshaft separately.

- The efficiencies of heat exchangers (for charge and discharge phases) are fixed to $90 \%$.

- Hot and cold water storages are considered as infinite volumes so their respective temperatures $80{ }^{\circ} \mathrm{C}$ and $15{ }^{\circ} \mathrm{C}$ remain constant. Hot/cold water mass flow and temperature are fixed at each inlet heat exchanger.

- Potential and kinetic energy are negligible.

\subsubsection{Analytical model}

The modelling of the global system is based on thermodynamic equations of each component of the system. The details of the equations are presented in the appendix. Air is considered for all the parameters calculated in the study (temperature, pressure, mass, mass flow) while it is written the superscript " $w$ " to indicate water as working fluid.

\subsubsection{Charge phase (energy consumption phase):}

Real work of compressor " $\mathrm{i}$ " is calculated by integrating the reversible work $(v \mathrm{~d} p)$ throughout the compression cycle which yields (figure 2):

$$
w_{c, i}=\left(\frac{n}{n-1} R T_{i n, c, i}\left(\beta_{c}(t)^{\frac{n-1}{n}}-1\right)\right) \frac{1}{\eta_{p o l}}
$$


Where $n$ is the polytropic index, $R$ is the gas constant, $\beta_{c}=\frac{P_{o u t, c}}{P_{i n, c}}$ is the compression ratio, $\eta_{p o l}$ is the polytropic efficiency and $T_{i n, c, i}$ is the air inlet temperature of the compressor " $i$ ".

As a result, the air compressor outlet temperature of each stage can be written as:

$$
\begin{aligned}
& T_{\text {out }, c, i}=T_{i n, c, i} \beta_{c}(t)^{\frac{n-1}{n}} \\
& \begin{array}{c}
w_{c, i} \text { 烈 } h_{\text {in }} \\
T_{\text {in }, c, i}
\end{array} \longrightarrow \begin{array}{l}
\dot{m}_{c} h_{\text {out }} \\
T_{\text {out }, c, i}
\end{array}
\end{aligned}
$$

Figure 2: Compressor block representation (input, output)

The difference between the hourly solar production and hourly building energy demand is calculated below (equation 3). This calculated energy $(\Delta E)$ imposes the input air mass flow to the compressor stages $\left(\dot{m}_{c}\right)$ which is function of the total compressor work $\left(\sum_{i=1}^{N c} w_{c, i}\right)$ and in other words function of the working reservoir pressure $\left(\beta_{c}\right)$ (equation 4).

$$
\begin{gathered}
\Delta E=E_{P V}(t)-E_{B D}(t) \\
\dot{m}_{c}=\frac{\Delta E}{\sum_{i=1}^{N C} w_{c, i} \Delta t}=\frac{E_{P V}(t)-E_{B D}(t)}{\sum_{i=1}^{N C} w_{c, i} \Delta t}
\end{gathered}
$$

In this study, the compressors are assumed to be mounted on the same crankshaft. Consequently, the revolution per minute is the same for all the compressors and is calculated by fixing the displacement volume of the first compressor stage (see assumptions):

$$
R P M_{C}=\frac{\dot{V}_{c, 1}}{V_{d, c, 1}} 60
$$

Where $\dot{V}_{c, 1}, V_{d, c, 1}$ are the air volume flow rate and displacement volume of the $1^{\text {st }}$ compressor stage respectively.

The displacement volume of the $i^{\text {th }}$ stage ( $i>1$ ) of compressor is calculated with the following equation:

$$
V_{d, c, i}=\frac{\dot{V}_{c, i}}{R P M_{c}} 60=\frac{\left(\dot{m}_{c} / \rho_{c, i}\right)}{R P M_{c}} 60
$$


Where $\rho_{c, i}$ is the air density of the compressor " $i$ "' which is related to the inlet compressor air pressure.

\subsubsection{Storage phase:}

As mentioned above the high pressure reservoir model is considered to be constantvolume $(W=0)$ and adiabatic $(\delta Q=0)$. The energy balance equation for the air entering the reservoir is as follows (figure 3):

$$
\mathrm{d}(m u)=+\dot{m}_{c} h_{i n} \mathrm{~d} t=h_{\text {in }} \mathrm{d} m
$$

Substituting the enthalpy and internal energy formulas into equation (7), results in the following solution:

$$
\frac{\mathrm{d} T}{\left(\gamma T_{\text {in,res }}-T_{\text {res }}\right)}=\frac{\mathrm{d} m}{m}
$$

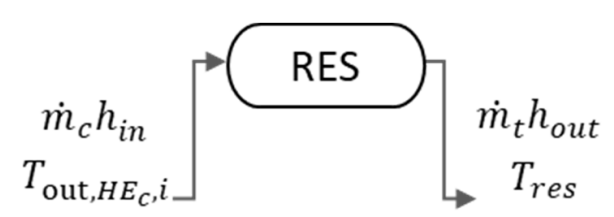

Figure 3: Reservoir block representation (input, output)

From this latter equation, the reservoir temperature is calculated as a function of the mass flow $\left(\dot{m}_{c}\right)$ entering the tank and its temperature $\left(T_{\text {in,res }}=T_{\text {out }, H E_{c}, i}\right)$.

The ideal gas equation is used to calculate the increase of reservoir pressure at each time step or the pressure decrease for air releasing phase (see appendix).

In the same way, as for the air entering phase, the energy conservation equation for the air leaving the high pressure reservoir is described by:

$$
\begin{gathered}
\mathrm{d}(m u)=-\dot{m}_{t} h_{\text {out }} \mathrm{d} t=+h_{\text {out }} \mathrm{d} m \\
\frac{c_{v} \mathrm{~d} T}{\left(c_{p} T_{\text {out }, \text { res }}-c_{v} T_{\text {res }}\right)}=\frac{\mathrm{d} m}{m}
\end{gathered}
$$

In this case, $T_{\text {out }, \text { res }}=T_{\text {res }}$ and equation (10) can be simplified to:

$$
\frac{\mathrm{d} T}{T_{\text {res }}}=(\gamma-1) \frac{\mathrm{d} m}{m}
$$




\subsubsection{Discharge phase (energy production phase):}

The turbine is based on a hypothetical model in this study due to the non-availability of the inlet high pressure turbine in the compressor/turbine market. Real work obtained from the turbine " $\mathrm{i}$ " and the outlet turbine air temperature are given by (see figure 4):

$$
\begin{gathered}
w_{t, i}=\left(\frac{n}{n-1} R T_{i n, t, i}\left(\beta_{t, i}(t)^{\frac{n-1}{n}}-1\right)\right) \eta_{p o l} \\
T_{\text {out }, t, i}=T_{i n, t, i} \beta_{t, i}(t)^{\frac{1-\mathrm{n}}{n}}
\end{gathered}
$$

Where $n$ is the polytropic index, $R$ is the gas constant, $\beta_{t}=\frac{P_{\text {out }, t}}{P_{\text {in, }, t}}$ is the expansion ratio and $\eta_{\text {pol }}$ is the polytropic efficiency. $T_{i n, t, i}, T_{o u t, t, i}$ are the air inlet/outlet temperature of the turbine "i".

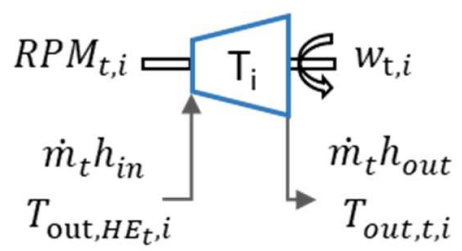

Figure 4: Turbine block representation (input, output)

Similar to compressor, the turbines are supposed to be mounted on the same crankshaft that is rotating at the same revolution per minute calculated by fixing the displacement volume of the first turbine stage.

The upper equations $(5,6)$ are also used for the discharge phase with the same assumptions:

$$
\begin{gathered}
R P M_{t}=\frac{\dot{V}_{t, 1}}{V_{d, t, 1}} 60 \\
V_{d, t, i}=\frac{\dot{V}_{t, i}}{R P M_{t}} 60=\frac{\left(\dot{m}_{t} / \rho_{t, i}\right)}{R P M_{t}} 60
\end{gathered}
$$

Where $R P M_{t}, \dot{V}_{t, 1}, V_{d, t, 1}$ are the turbines rotation per minute, air volume flow rate and displacement volume of the $1^{\text {st }}$ turbine stage respectively. $\dot{m}_{t}, \rho_{t, i}$ are the air mass flow entering the turbine and the air density of the turbine "i". 


\subsubsection{TES (Thermal energy storage) :}

A countercurrent heat exchanger was selected in order to cool the air during compression stages and to preheat it during expansion stages. The thermal energy storage in this study is assumed to be a large hot/cold volume reservoirs so their respective temperatures remain constant. The heat transfer during charge/discharge phases are calculated by (figure 5):

$$
\begin{aligned}
& \dot{Q}_{c, \mathrm{i}}=\dot{m}_{c} c_{p}\left(T_{i n, H E_{c}, i}-T_{o u t, H E_{c}, i}\right)=\dot{m}_{c o}^{w} c_{p}^{w}\left(T_{i n, H E_{c}, i}^{w}-T_{o u t, H E_{c}, i}^{w}\right) \\
& \dot{Q}_{t, i}=\dot{m}_{t} c_{p}\left(T_{i n, H E_{t}, i}-T_{o u t, H E_{t}, i}\right)=\dot{m}_{h o}^{w} c_{p}^{w}\left(T_{i n, H E_{t}, i}^{w}-T_{o u t, H E_{t}, i}^{w}\right)
\end{aligned}
$$

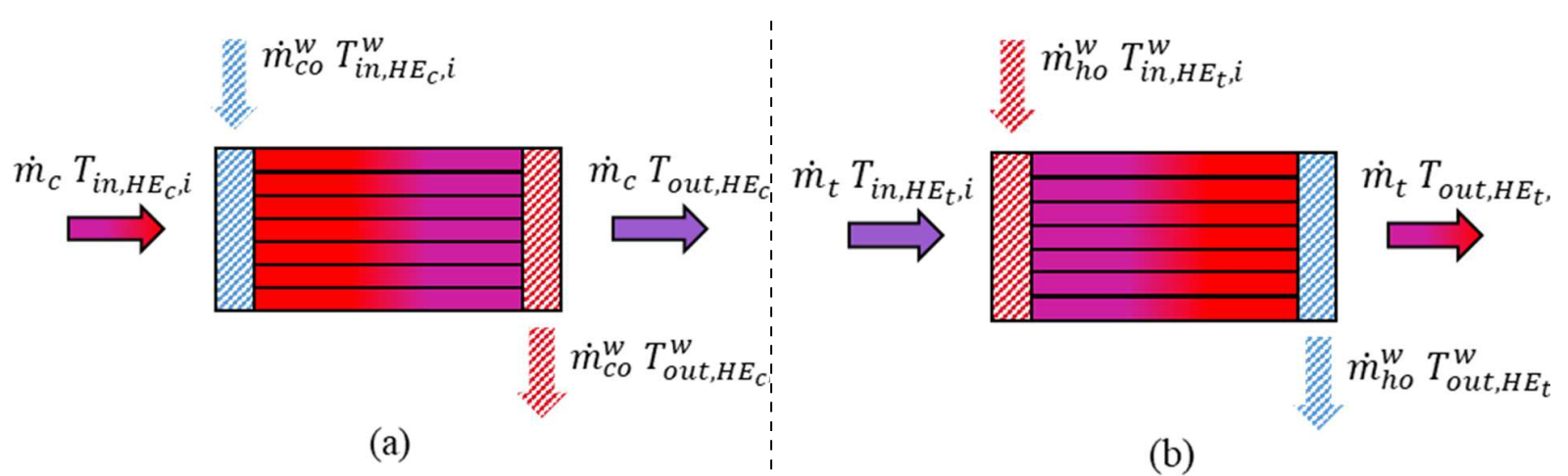

Figure 5: Heat exchanger representation during the charge phase (a) and the discharge phase (b)

With:

$$
\begin{gathered}
T_{\text {out }, c, i}=T_{i n, H E_{c}, i} \\
T_{\text {out }, H E_{c}, i}=T_{i n, c, i+1} \\
T_{\text {out }, r e s}=T_{i n, H E_{t}, i} \\
T_{\text {out }, H E_{t}, i}=T_{i n, t, i}
\end{gathered}
$$

Using the effectiveness-NTU method, the air outlet from the heat exchanger during the charge and discharge phases are described in the equations (22) and (23) respectively:

$$
\begin{gathered}
T_{o u t, H E_{c}, i}=T_{o u t, c, i}-\varepsilon_{H E, c}\left(T_{o u t, c, i}-T_{i n, H E_{c}, i}^{w}\right) \\
T_{o u t, H E_{t}, i}=T_{i n, H E_{t}, i}+\varepsilon_{H E, t}\left(T_{i n, H E_{t}, i}^{w}-T_{i n, H E_{t}, i}\right)
\end{gathered}
$$


The iterative approach used in this numerical global model to solve these equations above are represented in the diagram of figure 6.

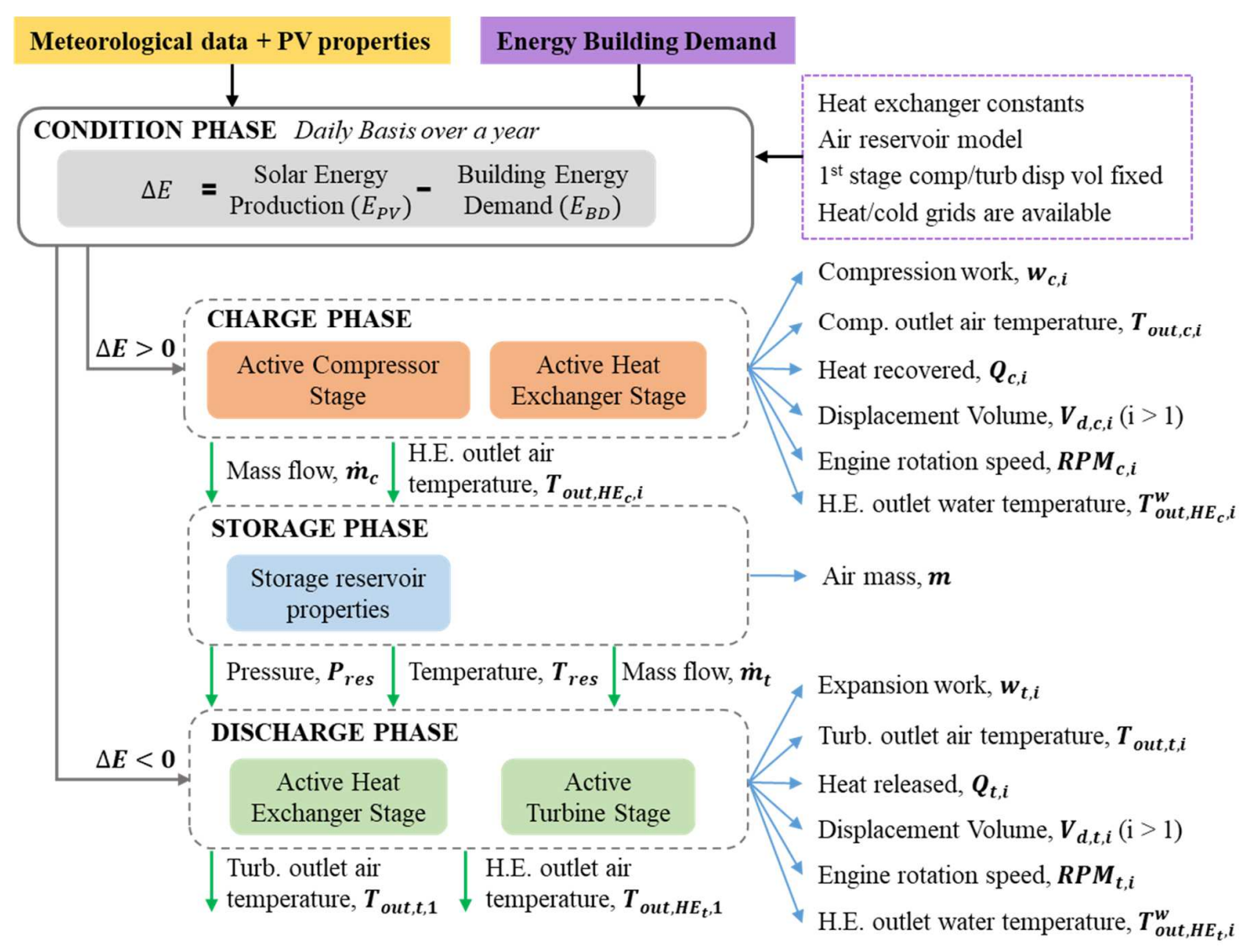

Figure 6: Block diagram that represents the global numerical code

\subsection{Global system operation}

The numerical model is based on three main conditions as follows (figure 7):

A. Solar panels supply the building load as a first priority (A).

B. If solar production is higher than the building load demand, then:

$\circ$ The rest $\left(E_{P V}-E_{B D}>0\right)$ is sent to the storage system (B).

$\bigcirc$ At the moment when the storage is full, all excess energy is sent to the electric grid (B').

C. If solar production is lower than the building load demand then:

$\circ$ The rest $\left(E_{P V}-E_{B D}<0\right)$ of building load demand is powered by micro AA-CAES storage system $(\mathrm{C})$ or by the electric grid $\left(\mathrm{C}^{\prime}\right)$ or both of them. 


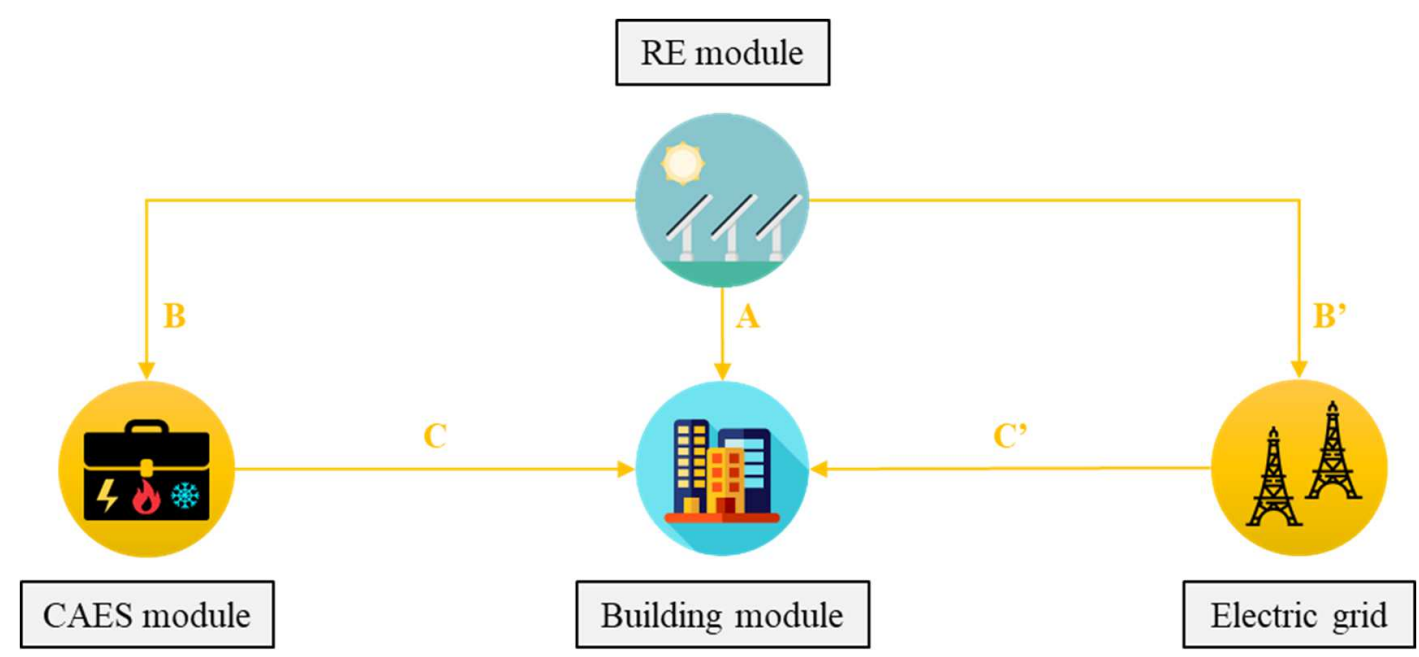

Figure 7: Global system operation

\section{Results and discussion}

\subsection{System performance analysis}

\subsubsection{Monthly energy source analysis}

Three different locations in France (Strasbourg, Nantes and Nice) are chosen in order to study different geographical scenarios for the same building model. As for the CAES system, three compressors and two turbines are chosen to be modeled. Figure 8 shows the monthly electrical energy building model demand and the monthly solar production for Nice. $1000 \mathrm{~m}^{2}$ is the main surface estimated for the solar panels whose efficiency is $20 \%$. Other input data and constraints required for the sizing procedure are listed in Table 1. "Nice" location is considered for figures 8 to 15 . 


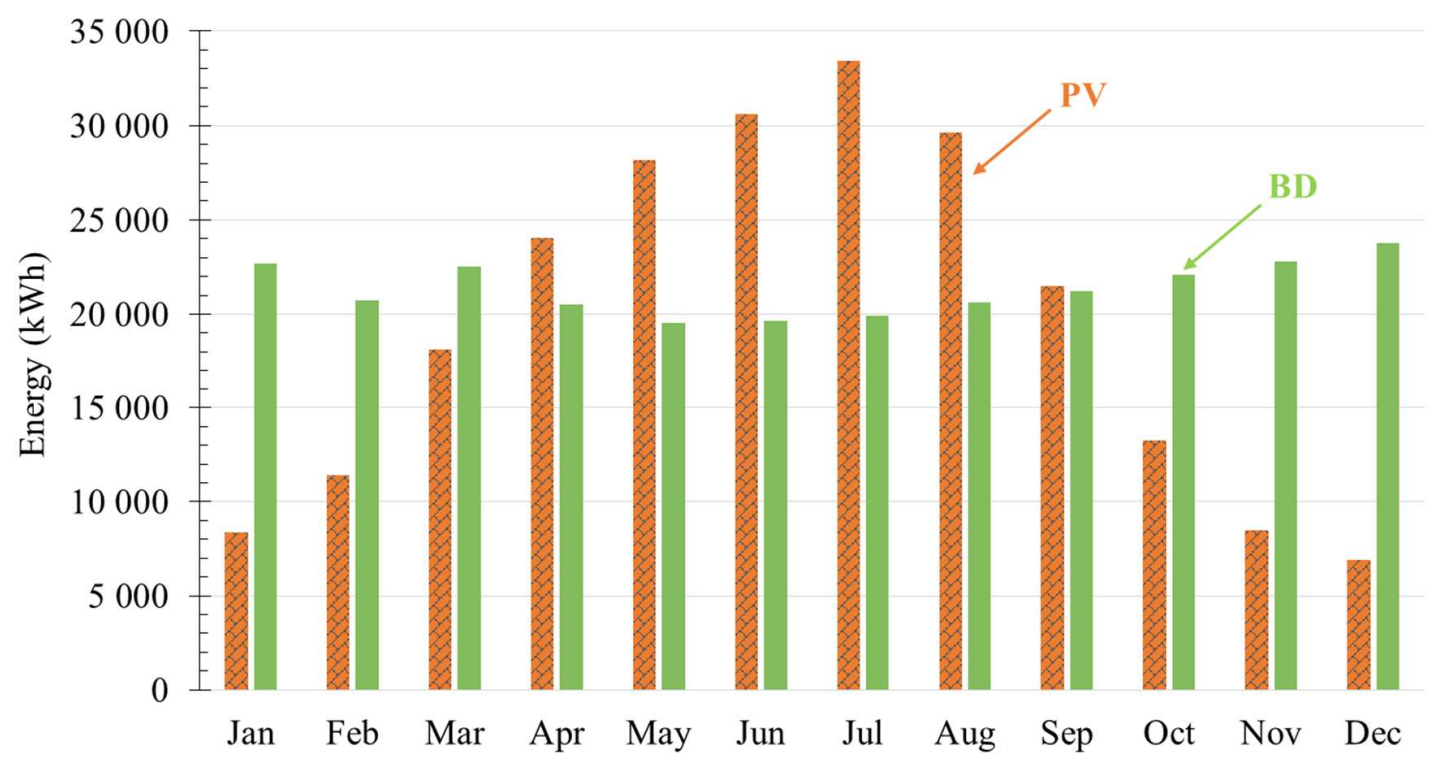

Figure 8: Monthly solar production $\left(E_{P V}\right)$ and electrical energy building demand $\left(E_{B D}\right)$ for Nice

Table 1: Input data and constraints

\begin{tabular}{llll}
\hline CAES unit & & PV unit & \\
Air reservoir volume & $50 \mathrm{~m}^{3}$ & Surface & $1000 \mathrm{~m}^{2}$ \\
Initial reservoir temperature & $20{ }^{\circ} \mathrm{C}$ & Efficiency & $20 \%$ \\
Max. air reservoir pressure & $200 \mathrm{bar}$ & & \\
Min. air reservoir pressure & $10 \mathrm{bar}$ & TES unit & \\
Number of compression stages & 3 & Inlet cold water temp & $15^{\circ} \mathrm{C}$ \\
Compression ratios $\left(\beta_{c, 1}, \beta_{c, 2}, \beta_{c, 3}\right)$ & $10,5,4$ & Inlet hot water temp & $80{ }^{\circ} \mathrm{C}$ \\
$1^{\text {st }}$ compressor displacement volume & $0.0006 \mathrm{~m}^{3}$ & Heat exchanger & \\
Number of expansion stages & 2 & efficiency & $90 \%$ \\
Expansion ratios $\left(\beta_{t, 1}, \beta_{t, 2}\right)$ & 5,10 & & \\
$1^{\text {st } \text { turbine displacement volume }}$ & $0.0006 \mathrm{~m}^{3}$ & & \\
Polytropic index & 1.4 & & \\
Polytropic efficiency & $80 \%$ & & \\
\hline
\end{tabular}

By applying the proposed numerical methodology, four different sources of energy can be represented in figure 9. It can be noticed that the energies derived directly from the solar production (PV self-consumption) and from the CAES system (Energy from storage) have the same behavior all over the year. This fact can be seen clearly during summer days (May, June, July and August) where energy derived from the storage scores the highest values (in August around $5600 \mathrm{kWh}$ ). It is worth mentioning that during June, July and August electrical energy building demand is totally answered and the rest of solar production is sent to the electrical grid (4000 kWh in July). 


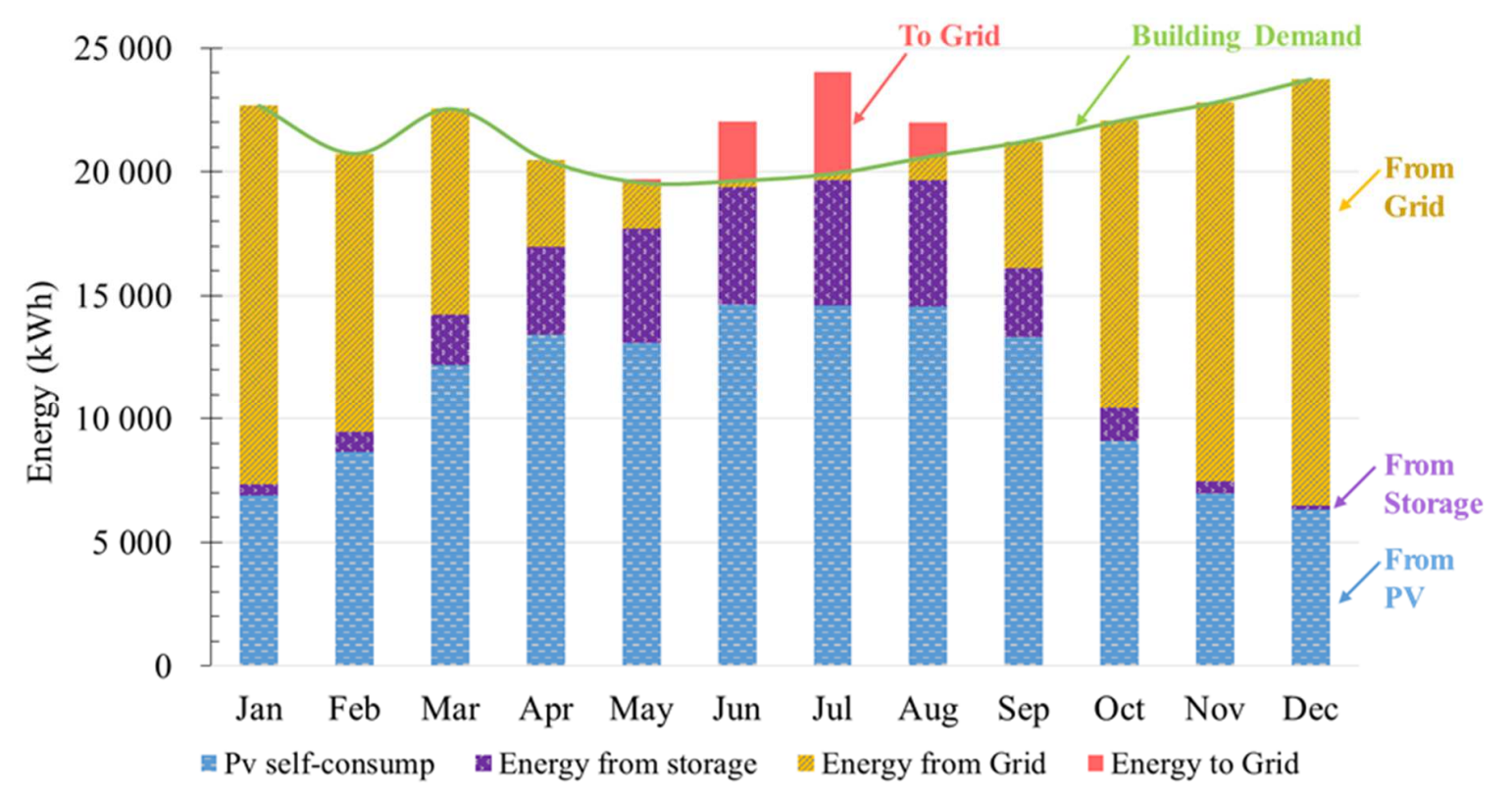

Figure 9: Monthly different sources of energy responding to building model electrical energy demand (Nice) obtained from the present simulations

It must be noted that figures 8 and 9 present the cumulative/sum of different sources of energy (solar, storage, energy from grid and energy to grid) and the energy building demand over each month of the year. The global system operation for different conditions (A, B, B', C, C') is analyzed at each hour time step where in many situations solar production does not answer the energy building demand. As a result, different sources of energy (solar production, storage and energy from the grid) must be used to answer the energy demand. For example, during the month of May, even though the sum of solar production is higher than the sum of building energy demand (figure 8), multiple sources of energy are used (figure 9).

\subsubsection{Daily energy source analysis}

As it can be seen in figure 10, the numerical model answers the building electrical energy demand (green) over the year by managing the three main conditions discussed in the global system operation (A, B, B', C, C'). The total energy consumed by the compressors (blue) is proportional to the solar production (yellow). The compressors/turbines are supposed to be intercooled/preheated by taking the assumption of heat and cold grids availability all over the year. The exergy associated to heat/cold thermal energy collected during charge and discharge phases $\left(Q_{c}, Q_{t}\right)$ are represented in figure 11. In some cases, compressed air is stored with an important temperature $\left(85^{\circ} \mathrm{C}\right)$ which does not allow it to be preheated before entering the turbine depending 
on the heat grid temperature used in this case. This explains why cold recuperated during discharge is less important than the heat collected during charge phase especially between the $90^{\text {th }}$ and $240^{\text {th }}$ day of the year (figure 11).

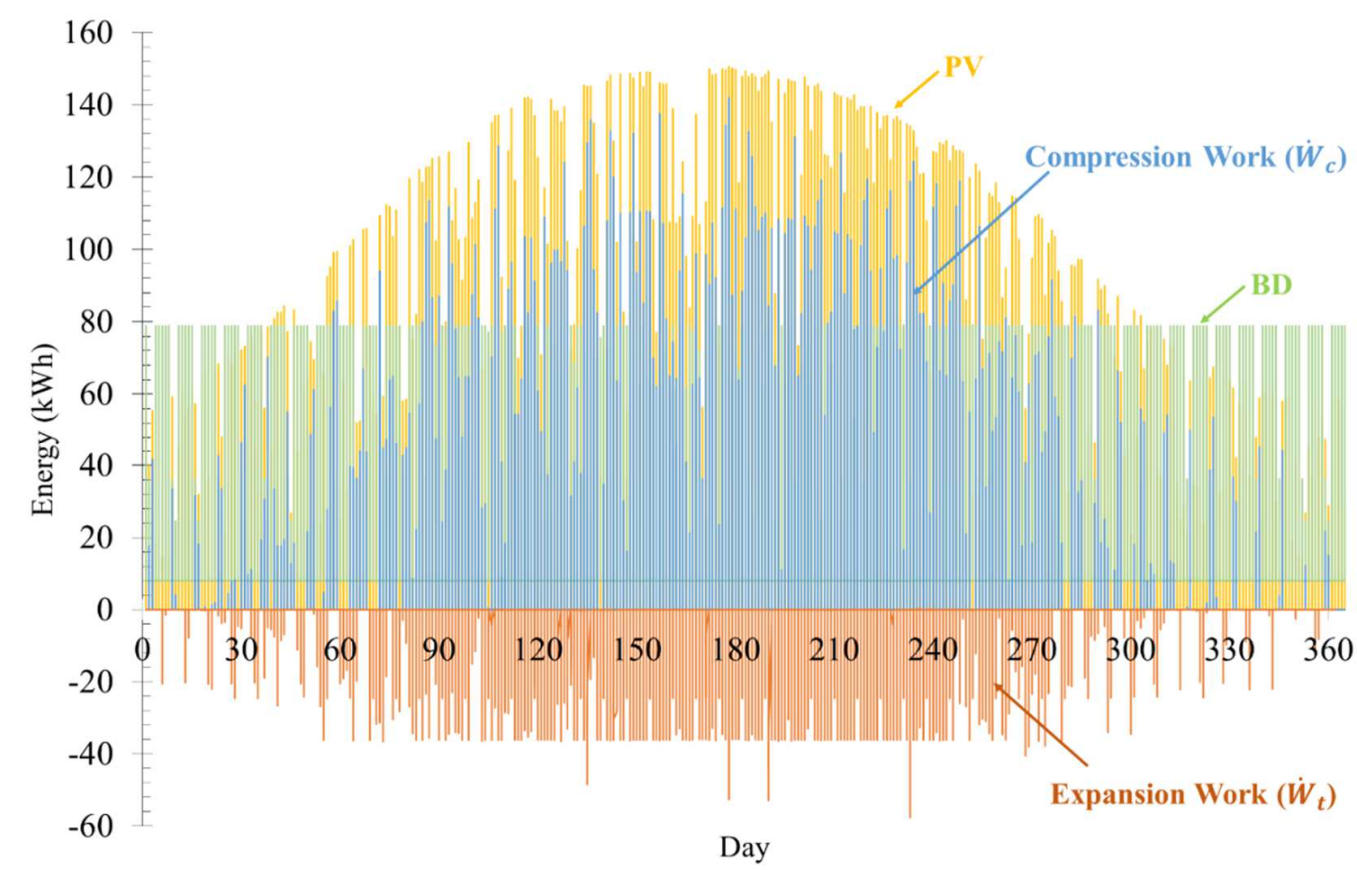

Figure 10: Daily solar energy (yellow) and building energy demand (green) with a representation for compensated compression work (blue) and recuperated turbine work (orange) over a year (Nice)

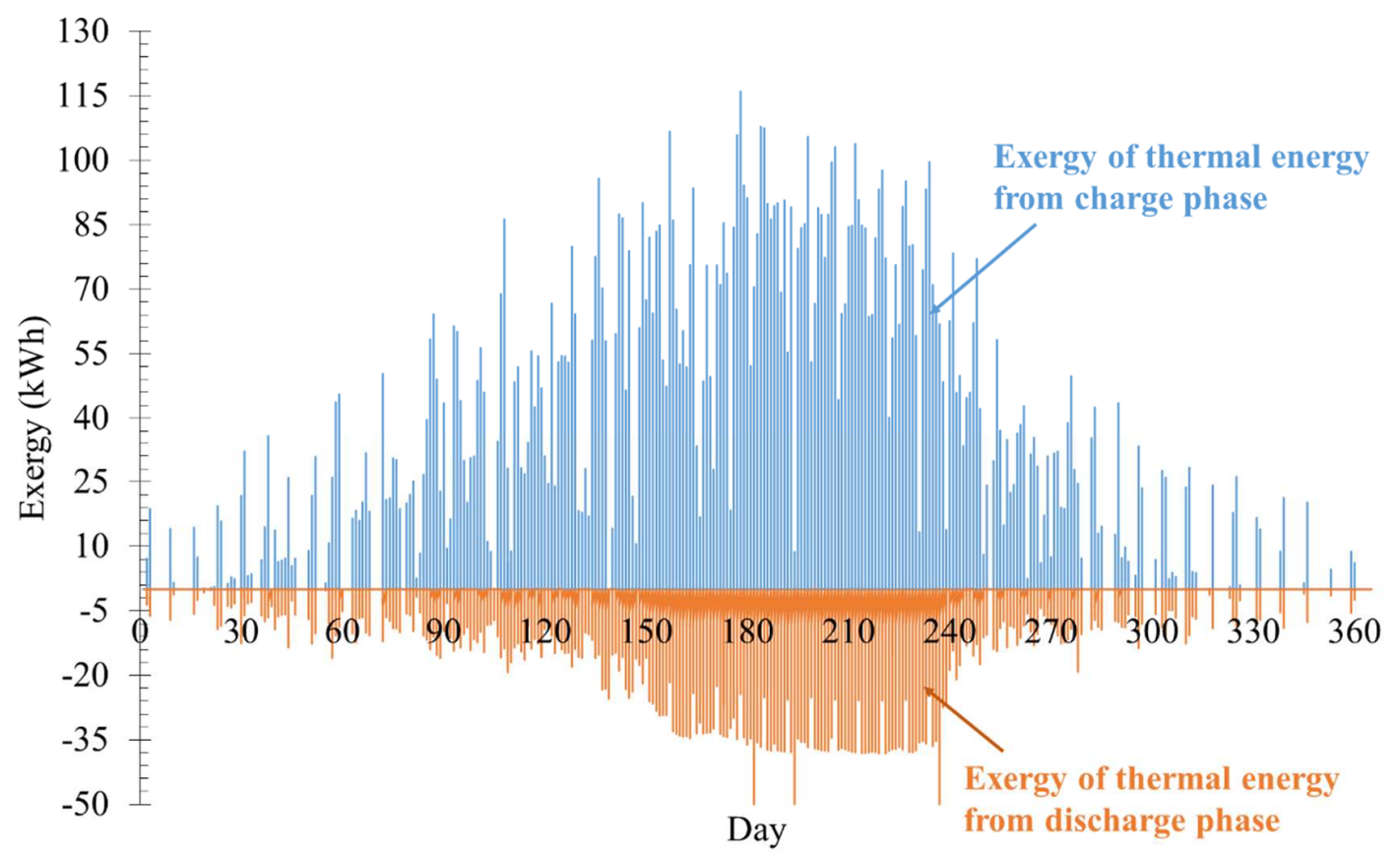


Figure 11: Daily thermal energy converted to mechanical energy during air compression phase (red) and air expansion phase (blue) over a year (Nice)

The month of July for Nice location is represented day by day in the figures 12 and 13. The daily sum of solar production in figure 12 is generally more important than the sum of energy building demand. This fact leads to the significate amount of the energy delivered to the grid (To grid) in figure 13.

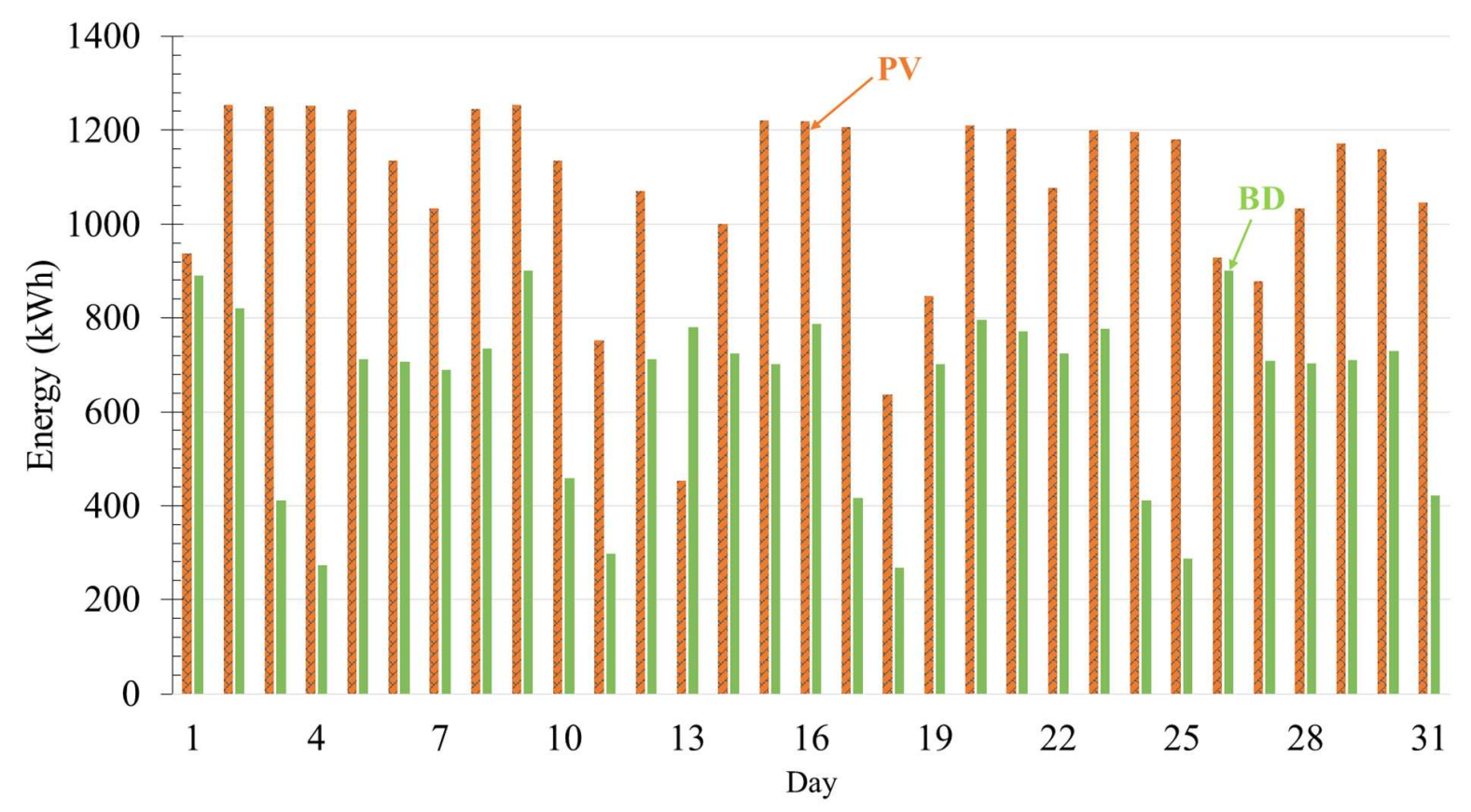

Figure 12: Daily solar production (PV) and energy building demand (BD) over July month (Nice) 


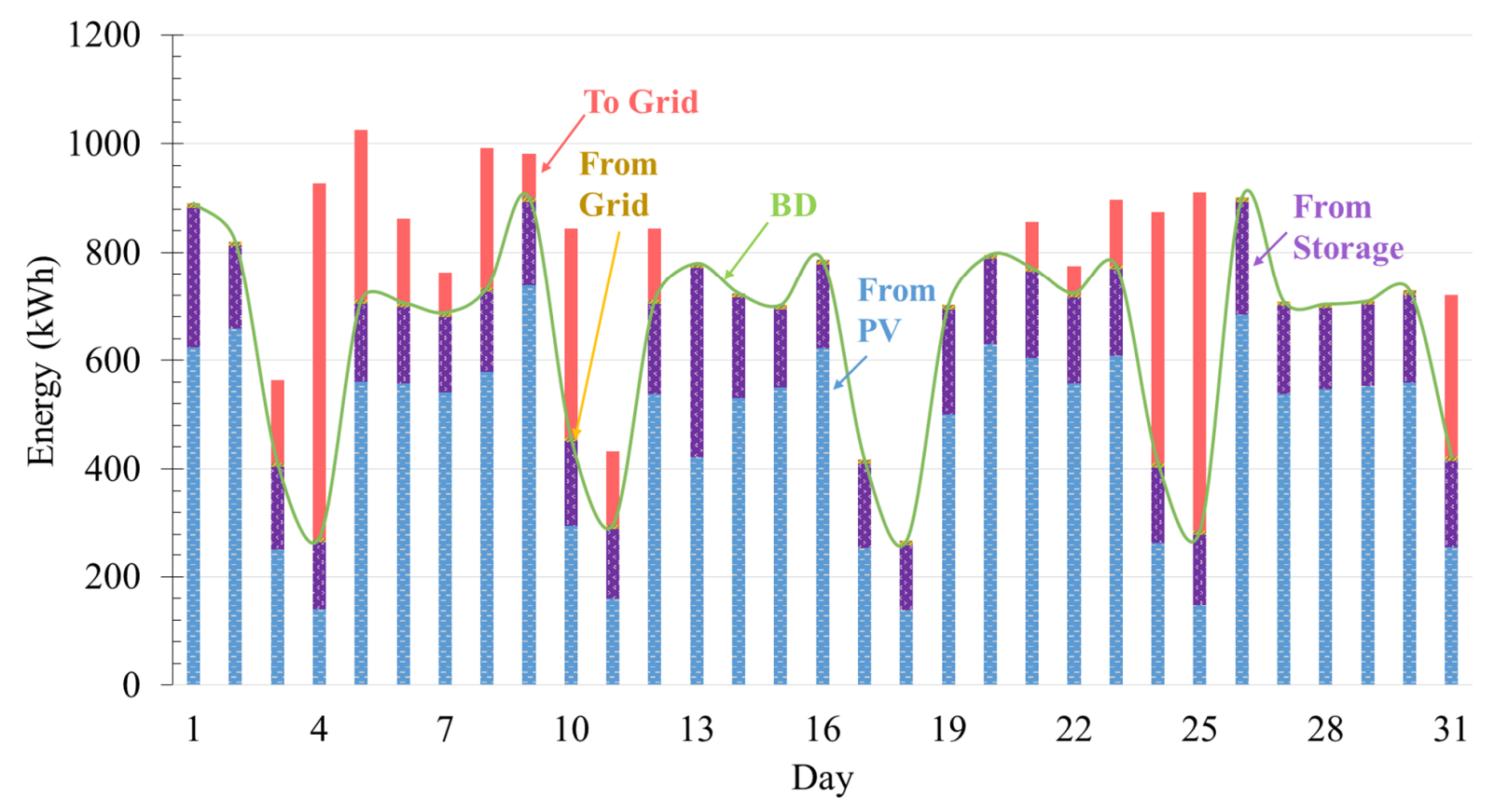

Figure 13: Daily different energy sources responding to building model energy demand over July month (Nice)

Figure 14 shows the hourly work compensated/recuperated during the air compression/expansion processes for the $17^{\text {th }}$ of July (for example). In addition, five examples of the crankshaft rotation for the compressor and the turbine are represented in figure 14. According to the plots, the three compressors (blue, orange, and grey) are in operating mode from 06:00 until 18:00 where the excess of solar energy is stored. On the other hand, during the night and without solar production the electrical energy demand is answered by the energy released by the turbines (dark blue and green). The crankshaft rotation of the turbines runs in the range of hundreds $(300,550)$ while the compressors in the range of thousands $(5200,15600,7400)$. 


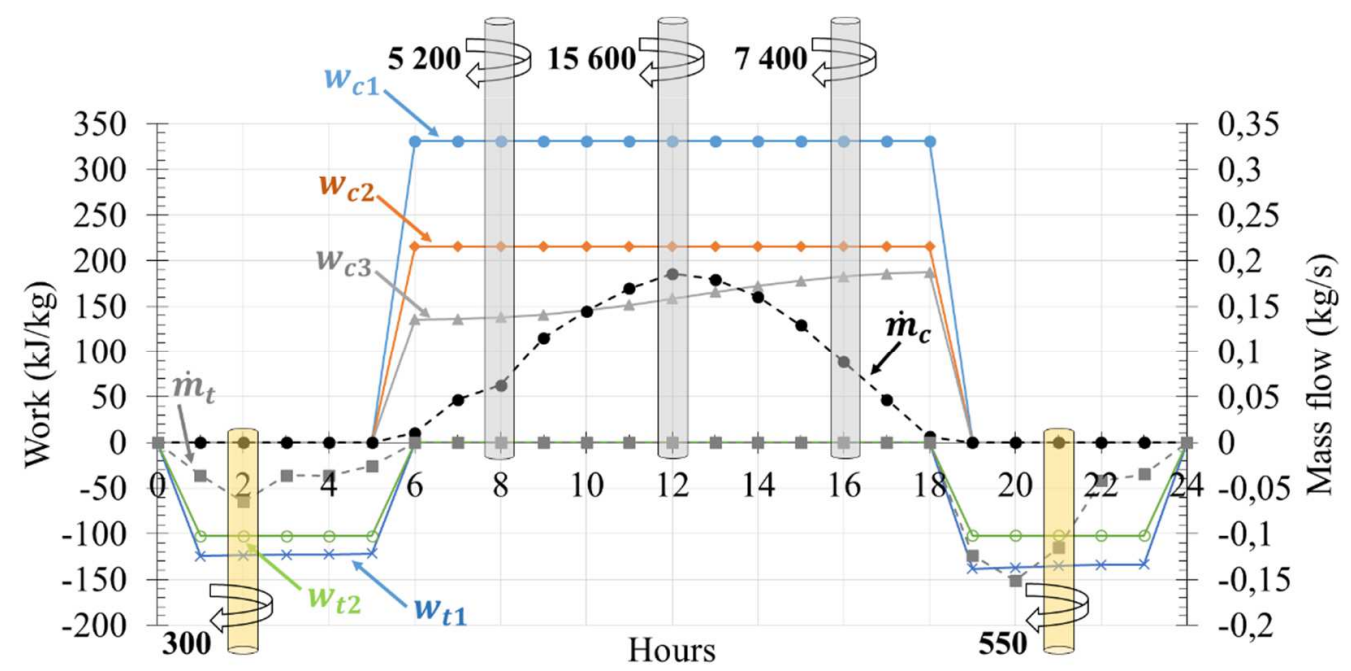

Figure 14: Hourly compression and expansion works with their respective mass flow compressed or released for the $17^{\text {th }}$ of July (Nice).

Calculated displacement volume of the 3 compressors and 2 turbines considered in this example for $17^{\text {th }}$ of July are listed in table 2 . Six working hours are showed in the table where during the night (1:00 till 5:00) the discharge phase takes place with the two turbines. In turn, for the charge phase during the morning (6:00 till 8:00), three compressors rotating at the same crankshaft speed with variable displacement volume are used.

Table 2: Example of calculated displacement volume of compressor and turbine for 9 hours during the $17^{\text {th }}$ of July

\begin{tabular}{cccccc}
\hline & \multicolumn{3}{c}{$\boldsymbol{V}_{\boldsymbol{d}, \boldsymbol{c}, \boldsymbol{i}}\left(\mathrm{m}^{3}\right)$} & \multicolumn{2}{c}{$\boldsymbol{V}_{\boldsymbol{d}, \boldsymbol{t}, \boldsymbol{i}}\left(\mathrm{m}^{3}\right)$} \\
\hline Time $(\mathbf{h})$ & $\mathbf{1}^{\text {st }}$ & $\mathbf{2}^{\text {nd }}$ & $\mathbf{3}^{\text {rd }}$ & $\mathbf{1}^{\text {st }}$ & $\mathbf{2}^{\text {nd }}$ \\
$1: 00$ & - & - & - & 0,0006 & $8,38 \mathrm{E}-05$ \\
$2: 00$ & - & - & - & 0,0006 & $8,46 \mathrm{E}-05$ \\
$3: 00$ & - & - & - & 0,0006 & $8,61 \mathrm{E}-05$ \\
$4: 00$ & - & - & - & 0,0006 & $8,70 \mathrm{E}-05$ \\
$5: 00$ & - & - & - & 0,0006 & $8,79 \mathrm{E}-05$ \\
$6: 00$ & 0,0006 & $6,39 \mathrm{E}-05$ & $1,31 \mathrm{E}-05$ & - & - \\
$7: 00$ & 0,0006 & $6,39 \mathrm{E}-05$ & $1,31 \mathrm{E}-05$ & - & - \\
$8: 00$ & 0,0006 & $6,39 \mathrm{E}-05$ & $1,31 \mathrm{E}-05$ & - & - \\
$9: 00$ & 0,0006 & $6,39 \mathrm{E}-05$ & $1,31 \mathrm{E}-05$ & - & - \\
\hline
\end{tabular}

\subsubsection{Performance criteria}

In order to analyze different results of the micro AA-CAES system, three indicators are defined in this study as follows: 
- Electrical Load Management (E.L.M) which reflects the energy part that answered the total electric energy consumption based on solar production and energy coming from storage. This indicator is affected by the solar panel surface and the solar irradiation (location) and is described as follows:

$$
\text { E. L. } M=\frac{\operatorname{Min}\left(E_{P V}, E_{B D}\right)+W_{t}}{E_{\text {total consump }}}=1-\frac{\left(E_{\text {from grid }}+E_{\text {to grid }}\right)}{E_{\text {total consump }}}
$$

Where $E_{\text {total consump }}$ is the total building model electrical energy demand.

- Coverage Ratio (C.R) which reflects the percentage of total energy demand covered only by the compressed air energy storage (AA-CAES).

$$
C \cdot R=\frac{W_{t}}{E_{\text {total consump }}}
$$

- System Efficiency (S.E) which gives an idea about the compensated/recuperated work during compression/expansion phases respectively.

$$
S . E=\frac{W_{t}}{W_{c}}
$$

It can be noticed from the equations (24-25) that E.L.M. and C.R. are affected by the solar panel surface and the solar irradiation (location) whereas S.E. is function of the polytropic index which has an impact on the compression and expansion work.

In figure 15, the calculated AA-CAES E.L.M for this case study (fixed PV area and reservoir volume) is around $64.3 \%$ where PV self-consumption part took the most important part (52.3\%). It is important to mention that beside that the energy delivered by the storage system (12\%), electric grid is used to cover the rest of the building energy demand (35.7\%).

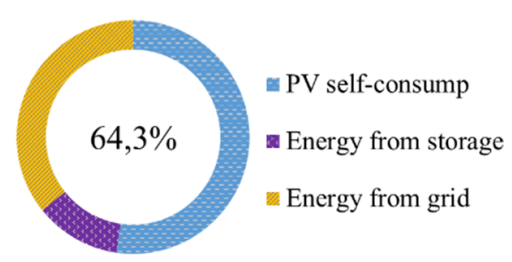

Figure 15: Average yearly Electrical Load Management (E.L.M) of the CAES system (Nice)

\subsection{Parametric analysis}


The following study concentrates on the analysis of the three indicators mentioned above (equation $24,25,26$ ). In the section below, the calculated results which primarily are based on input parameters showed acceptable fluctuation while varying these inputs. $10 \%$ variation of the heat exchanger efficiency resulted in a range of fluctuation between $0.4 \%$ and $3.9 \%$ for the Electrical Load Management (E.L.M.), the Coverage Ratio (C.R.) and the System Efficiency (S.E.). Similarly, $10 \%$ variation of the PV unit efficiency and polytropic efficiency resulted in a fluctuation between $0.3 \%$ and $13 \%$ and between $2.9 \%$ and $15 \%$ respectively.

\subsubsection{Geographical scenario, PV surface and reservoir volume/pressure influence}

The three indicators defined above are calculated with varying three main parameters: geographical location (Strasbourg, Nantes and Nice), PV surface $\left(500 \mathrm{~m}^{2}-5000 \mathrm{~m}^{2}\right)$ and storage volume $\left(5 \mathrm{~m}^{3}-50 \mathrm{~m}^{3}\right)$. Each city is represented by a color in figures 16 and 17 . With a $50 \mathrm{~m}^{3}$ fixed storage volume, it can be seen from figure 16 that the increase of PV surface induces also an increase for the three indicators with different behaviors. The System Efficiency (S.E.) converges around the value of $34 \%$ from $1500 \mathrm{~m}^{2}$ of PV surface (figure 16). On the contrary, the Electrical Load Management (E.L.M.) and the Coverage Ratio (C.R.) have the same shape whatever the city and are affected by the increase of PV surface and the solar energy production (for a fixed PV surface). As an example, for $1000 \mathrm{~m}^{2}$ of PV panel area E.L.M. is between $50 \%$ and $64 \%$ and the C.R. is between $8 \%$ and $12 \%$.

These numerical results show a fair agreement with the ones presented in the numerical model developed by Simpore et al. [26]. The latter simulated AA-CAES system with one compression/expansion stage coupled to photovoltaic panel and building model. Based on Simpore et al. [26], the calculated system efficiency is around $40 \%$. 


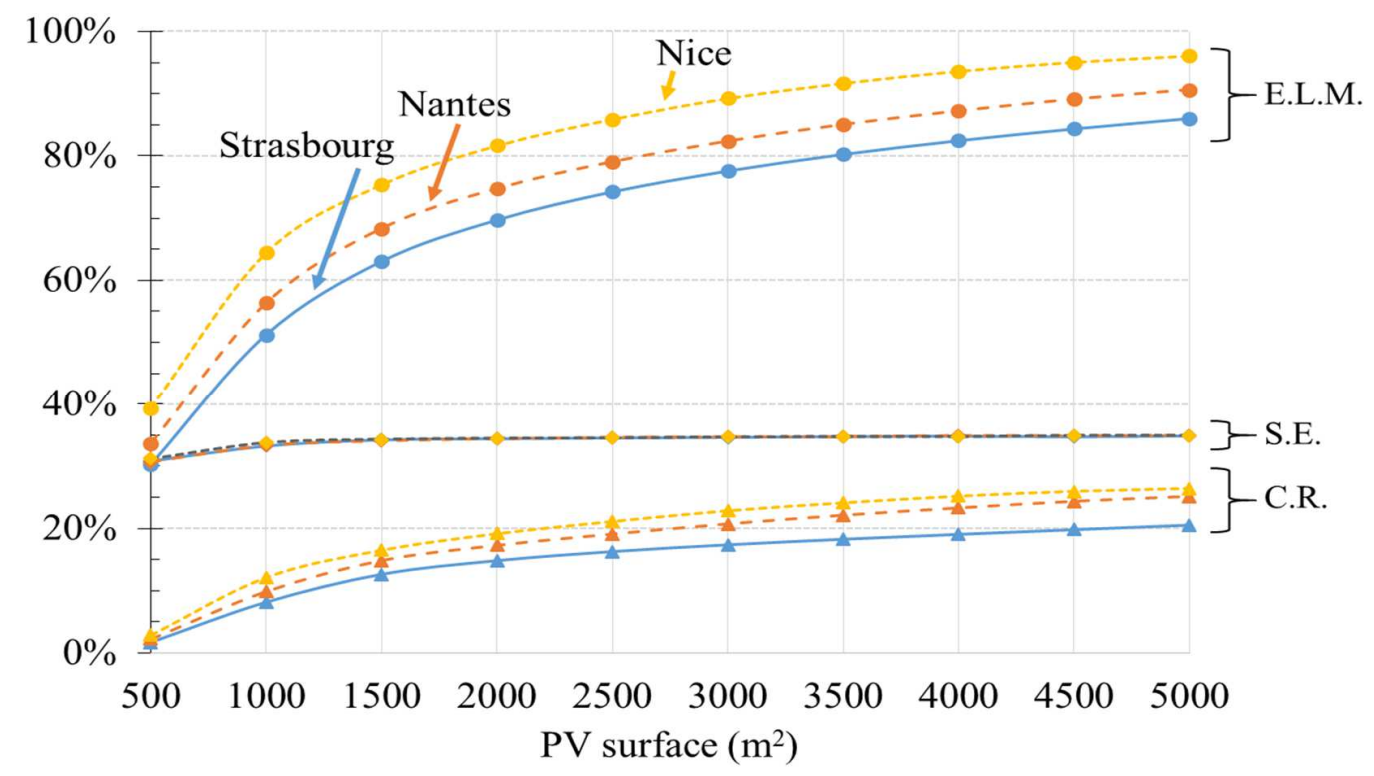

Figure 16: Electrical Load Management (E.L.M), Coverage Ratio (C.R) and System Efficiency (S.E) for three different locations with constant reservoir volume of $50 \mathrm{~m}^{3}$ (Strasbourg, Nantes, Nice)

The impacts of the storage volume and pressure are investigated taking Nice as a location. Variable volume and constant pressure are considered in figure 17. In the other way, variable pressure and constant volume were taken into consideration in figure 18. Fixed PV panel area of $1000 \mathrm{~m}^{2}$ is used for both studies. In both figures 17 and 18, total compression/expansion works are also represented. The highest E.L.M and C.R. values can be obtained with $50 \mathrm{~m}^{3}$ of reservoir volume (for 200 bar) and with 100 bar of pressure reservoir (for $50 \mathrm{~m}^{3}$ ). Figures 17 and 18 point out that the storage volume and pressure for a fixed PV surface have a low impact on global AA-CAES system. On the other hand, S.E. is highly affected specially with the storage pressure variation because its increase causes the increase of the total compression work which reduces the S.E. (equation 26) as it can be seen in figure 18 . 


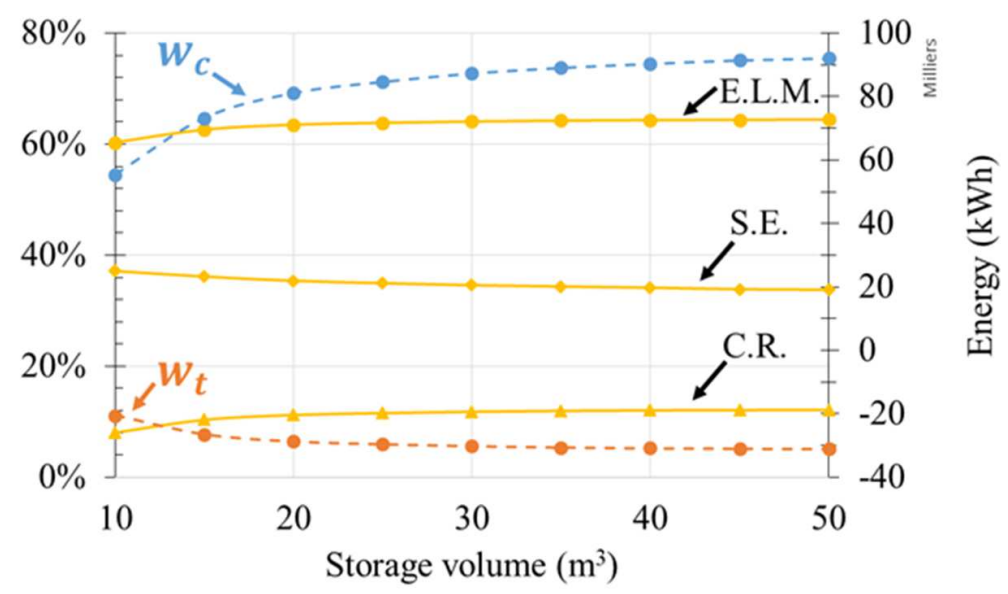

Figure 17: Electrical Load Management (E.L.M), Coverage Ratio (C.R) and System Efficiency (S.E) variation in function of reservoir volume with constant PV area of $1000 \mathrm{~m}^{2}$ (Nice)

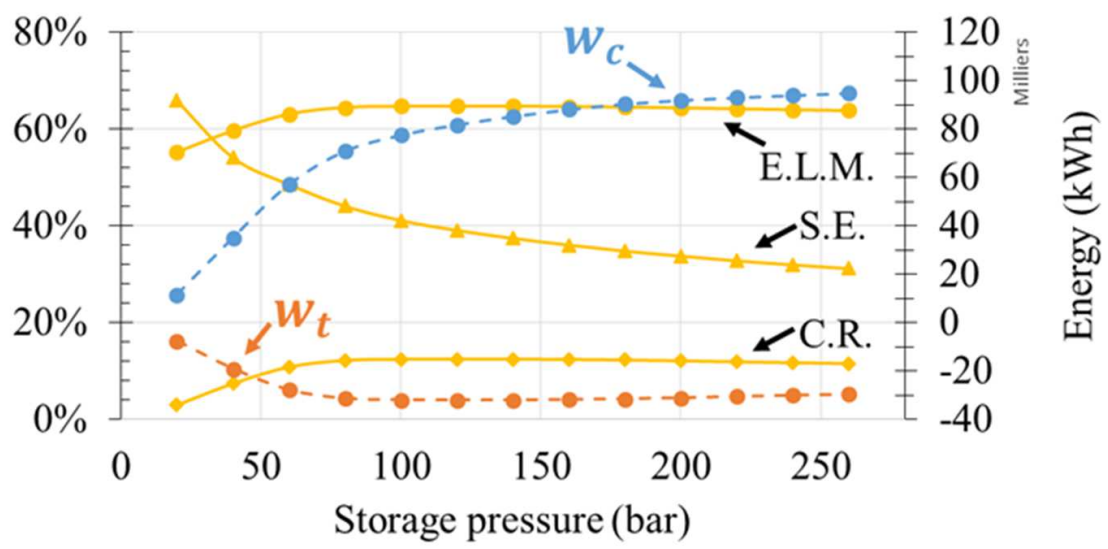

Figure 18: Electrical Load Management (E.L.M), Coverage Ratio (C.R) and System Efficiency (S.E) variation in function of reservoir pressure with constant PV area of $1000 \mathrm{~m}^{2}$ and storage volume of $50 \mathrm{~m}^{3}$ (Nice)

\subsubsection{Polytropic index influence}

Figure 19 represents the same parameters seen in figure 16 for Nice location and with the assumption listed in table 1 but with varying the polytropic index. From equation (26) and (14), the System Efficiency (S.E) is function of work provided by the turbines depending of the polytropic index. This can explain the huge gap (23\%) between an adiabatic S.E ( $n$ $=1.4)$ and isothermal S.E. $(n=1)$ with the increase of the PV surface. Also, a low impact (between $1.6 \%$ and $3.6 \%$ ) is seen on E.L.M and C.R indicators. 


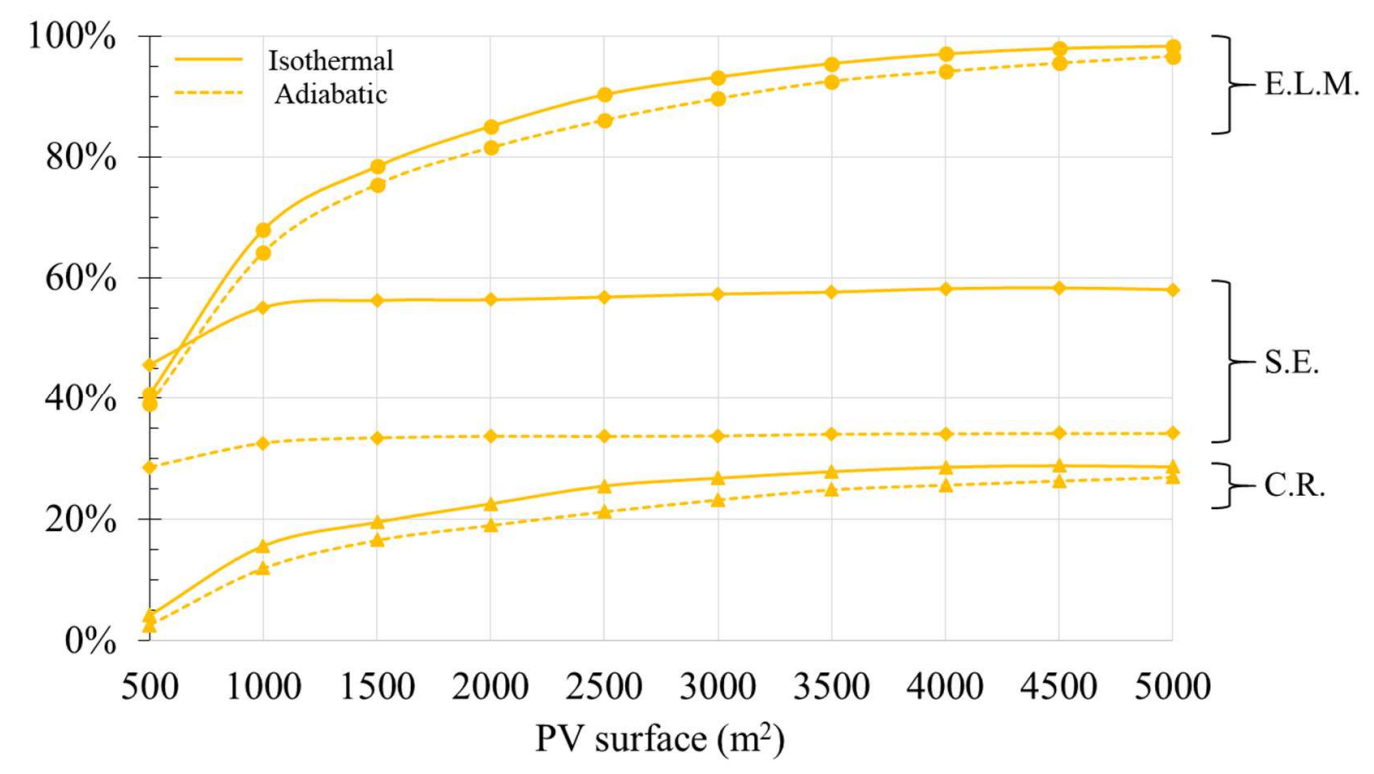

Figure 19: Electrical Load Management for adiabatic and isothermal CAES system according to Nice with constant reservoir volume of $50 \mathrm{~m}^{3}$

\section{Cost estimates}

\subsection{Micro CAES market current situation}

Even though C-CAES exists for more than 40 years, the micro CAES technology is still in development phase. In the last decade, small scale compressed air energy storage has been an interesting topic for many scientific researchers trying to find solutions to the technical restrictions and limitations presented by the storage systems. Numerical sizing tool are developed to study different system configurations in order to find the best system efficiency or to make the energy storage system more profitable within different energy context. In addition, experimental work are concentrated for the storage phase of a small power energy storage system. Beside these theoretical and experimental investigations, the compressed air market presents a missing piece to accomplish this micro energy storage system. In fact, the high inlet pressure turbine machine (> 40 bar) is not available in the market which made this system not applicable in the short term.

\subsection{Levelized cost of energy for micro CAES system}


In this analysis, the micro AA-CAES system composed of commercial units with specific working parameters is compared to the technology developed by LightSail Energy. The latter developed a reversible air motor that compress/expand air quasi-isothermally up/from 200 bars [15,31]. The LCOE calculator measures the cost of these two technologies over a period of 20 years. The main inputs used for this analysis are listed in table 3 .

Even though high inlet pressure turbine does not exist commercially in the market, two micro CAES systems with two different storage pressure (40 and 200 bar) are analyzed, in order to highlight the storage pressure influence on the total cost. Table 4 presents the capital expenditure (CAPEX) for each storage system with specific working parameters fixed by the supplier or the manufacturer.

Table 3: Main LCOE calculator inputs

\begin{tabular}{lcc}
\hline & $\begin{array}{c}\text { Micro } \\
\text { AA-CAES_I_II }\end{array}$ & $\begin{array}{c}\text { LightSail } \\
\text { Energy }\end{array}$ \\
\hline Electrical efficiency (\%) & 30 & 55 \\
OPEX (\% of CAPEX) & 2 & 2 \\
Cost of the turbine (\% of & 120 & - \\
cost comp) & (Estimation) & 2 \\
General inflation (\%) & 2 & 18 \\
Supplier's margin (\%) & 20 & 10 \\
Transportation $(\%)$ & - & \\
\hline
\end{tabular}


Table 4: CAPEX of three storage systems with different working parameters

\begin{tabular}{lccc}
\hline & Micro & Micro & LightSail \\
& AA-CAES_I & AA-CAES_II & Energy \\
\hline Storage pressure (bar) & 40 & 200 & 200 \\
Power (kW) & 23,5 & 23,5 & 200 \\
Energy (for 8h) $\mathrm{kWh}$ & 188 & 188 & 1600 \\
Polytropic index & 1,4 & 1,4 & 1,185 \\
Potentiel energy $\left(\mathrm{kWh} / \mathrm{m}^{3}\right)$ & 2,53 & 15,17 & 20,02 \\
Reservoir volume $\left(\mathrm{m}^{3}\right)$ & 74 & 12 & 80 \\
CAPEX $(€)$ & 957396 & 215656 & 623040 \\
\hline
\end{tabular}

In figure 20 , the levelized cost of energy ( $€ / \mathrm{kWh}$ delivered) calculated for each technology, is shown. It is worth noting that the total LCOE varies strongly with the storage pressure parameter. This is justified by the important cost of the commercial compressed air reservoir. The costs resulted of this study (€/kWh delivered) of micro AA-CAES_I_II and LightSail Energy technologies are respectively: $1.84 € / \mathrm{kWh}, 0.57 € / \mathrm{kWh}, 0.25 € / \mathrm{kWh}$. 


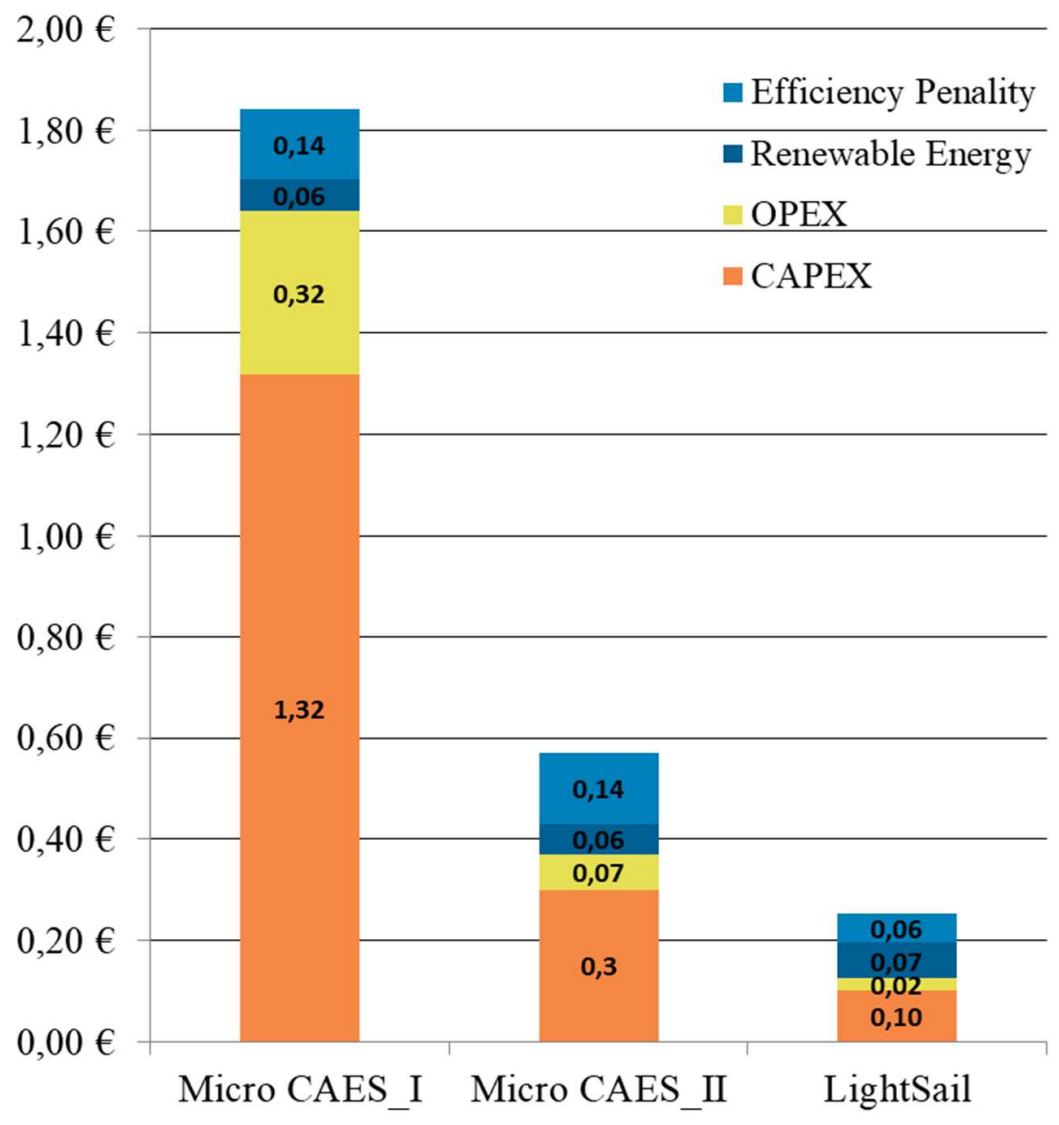

Figure 20: LCOE for micro CAES (I/II) and LighSail Energy technology

\section{Conclusions and perspectives}

In this paper, a novel micro advanced adiabatic compressed air energy storage system (AACAES) composed of commercial units that are available in the market, is proposed in order to answer electrical energy demand for a building model.

Different design parameters are grouped in order to have a global numerical sizing tool based on solving energy and heat transfer equations in an iterative approach using Excel VBA. This study allowed:

- To highlight the interest in this compressed air energy storage system integrated with photovoltaic power plant for building application. 
- To develop a global sizing tool in order to simulate commercial units available in the market on a daily basis over a year. This model offers an important flexibility around the input design parameters.

- To propose a new hypothetical turbine machine model that does not exist commercially in the market.

- To have a closer look on compressor and turbine behavior: calculated mass flow, displacement volume and engine rotation speed based on the hourly solar production and hourly electrical energy building demand.

- To study the influence of system sizing on different indicators (Electrical Load Management, System Efficiency and Coverage Ratio) on the micro advanced adiabatic compressed air energy storage. In best energetic case configuration, the Electrical Load Management, System Efficiency and Coverage Ratio are expected to be respectively equal to $64.4 \%, 33.7 \%$ and $12.14 \%$.

- The system efficiency calculated in this paper shows a fair agreement with the one resulted numerically by Simpore et al. [26].

- To examine a levelized cost of energy analysis for the studied micro AA-CAES. This analysis showed the technological barriers which the energy storage system has to overcome. These limitations are mainly due to the important cost of the high pressure reservoir and to the non-availability of high inlet pressure turbine commercially. Based on LCOE calculator, the increase in the storage pressure from 40 bar to 200 bar leads to 1.27 $€ / \mathrm{kWh}$ of cost reduction.

Our future scientific work will highlight on the connected global system where electric, heat and cold grid are connected to the storage system integrated with photovoltaic panel responding to the energy building needs. This work will focus more on the sizing of the thermal energy storage by simulating hot and cold building demand. In addition, the life cycle analysis (LCA) of the micro AA-CAES system where energy output-based emission factor approach suggested by Chicco et al. [32] is taken into consideration. Future investigations should also be carried out to study the quasiisothermal compressed air energy storage system and compare it with the studied micro AA-CAES studied system. 
CETHIL laboratory and AIA Life Designers company have the intention to develop the first small scale CAES prototype dedicated to building applications.

\section{Acknowledgment}

This scientific research was financed by:

- ADEME (French Environment \& Energy Management Agency) and AIA LIFE DESIGNERS (France) within the framework of the AIR4POWER project.

- ANRT (The National Association of Research and Technology) and AIA LIFE DESIGNERS (France) for the PhD grant within the framework of a CIFRE convention. 


\section{References}

[1] International Energy Agency. World energy outlook 2018.

[2] International Energy Agency. Renewables 2018 - Analysis and forecasts to 2023. Executive summary; 2018.

[3] BP energy outlook. BP Statistical review of world energy. 10 December 2018.

[4] Venkataramani G, Wang J. A review on compressed air energy storage - A path way for smartgrid and polygeneration. Renewable and Sustainable Energy Reviews 2016;62:895-907.

[5] French Alternative Energies and Atomic Energy Commission (CEA). Stationary energy storage. France: Office of the Atomic Energy and Alternative Energies; 18 october 2012.

[6] Luo X, Wang J, Dooner M, Clarke J. Overview of current development in electrical energy storage technologies and the application potential in power system operation. Applied Energy 2015; 137:511-36.

[7] Budt M, Wolf D, Span R, Yan J. A review on compressed air energy storage: Basic principles, past milestones and recent developments. Applied Energy 2016;170:250-68.

[8] Wang J, Lu K, Ma L, Wang J, Dooner M, Miao S, Li J, WAng D. Overview of Compressed Air Energy Storage and Technology Development. Energies 2017;10:991. https:// doi:10.3390/en10070991.

[9] Chen L, Zheng T, Mei S, Xue X, Liu B, Lu Q. Review and prospect of compressed air energy storage system. Journal of Modern Power Systems and Clean Energy 2016;4(4):529-541. https://doi:10.1007/s40565-016-0240-5.

[10] Nakhamkin M, Chiruvolu M, Daniel C. Available Compressed Air Energy Storage (CAES) Plant Concepts. Enegy storage and power corporation (ESPC) 2010.

[11] Ter-Gazarian A. Energy storage for power systems. London: Peter Peregrinus Ltd; 1994.

[12] Crotogino F, Mohmeyer K-U, Scharf R. Huntorf CAES: more than 20 Years of successful operation. In: Proceedings of SMRI Spring Meeting, Orlando, Florida, USA; 15-18 april 2001.

[13] Barbour E, Mignard D, Ding Y, Li Y. Adiabatic Compressed Air Energy Storage with packed bed thermal energy storage. Applied Energy 2015;155:804-15.

[14] The French National Institute for Industrial Environment and Risks (Ineris). Underground storage of compressed air in the context of the energy transition. France: Ground and Subsoil Risk Management; 2016. 
[15] Crane S, Fong D, Berlin E, inventor; LightSail Energy Inc., Energy storage system utilizing compressed gas. United States patent US 8,247,915 B2.2012 Aug 21.

[16] Lemofouet S. Investigation and optimization of hybrid electricity storage systems based on compressed air and supercapacitors. Doctoral thesis. EPFL, 2006.

[17] Kim Y. Novel concepts of compressed air energy storage and thermo-electric energy storage. Doctoral thesis. EPFL, 2012.

[18] Xue H, White A. A comparative study of liquid, solid and hybrid adiabatic compressed air energy storage systems. Journal of Energy Storage 2018;18(2018):349-359.

[19] Liu J, Wang J. A comparative research of two adiabatic compressed air energy storage systems. Energy Conversion and Management 2015;108(2016):566-578.

[20] Chen L, Hu P, Sheng C, Xie M. A novel compressed air energy storage (CAES) system combined with pre-cooler and using low grade waste heat as heat source. Energy 2017;131(2017):259-266.

[21] Hartmann N, Vöhringer O, Kruck C, Eltrop L. Simulation and analysis of different adiabatic Compressed Air Energy Storage plant configurations. Applied Energy 2011;93:54148.

[22] Zhang Y, Yang K, Li X, Xu J. The thermodynamic effect of air storage chamber model on Advanced Adiabatic Compressed Air Energy Storage System. Renewable Energy 2013;57:469-478.

[23] Guo C, Xu Y, Zhang X, Guo H, Zhou X, Liu C, Qin W, Li W, Dou B, Chen H. Performance analysis of compressed air energy storage systems considering dynamic characteristics of compressed air storage. Energy 2017;135:876-88.

[24] Li Y, Wang X, Li D, Ding Y. A trigeneration system based on compressed air and thermal energy storage. Applied Energy 2012;99:316-23.

[25] Jannelli E, Minutillo M, Lubrano Lavadera A, Falcucci G. A small-scale CAES (compressed air energy storage) system for stand-alone renewable energy power plant for a radio base station: A sizing-design methodology. Energy 2014;78:313-22.

[26] Simpore S, Garde F, David M, Marc O, Castaing-Lasvignottes J. Design and Dynamic Simulation of a Compressed Air Energy Storage System (CAES) Coupled with a Building, an Electric Grid and a Photovoltaic Power Plant. In: Proceedings of 12th REHVA World Congress, Denmark; 25 may 2016. 
[27] Lv S, He W, Zhang A, Li G, Luo B, Liu X. Modelling and analysis of a novel compressed air energy storage system for trigeneration based on electrical energy peak load shifting », Energy Conversion and Management 2017;135:394-401.

[28] Wang S, Zhang X, Luwei Y, Zhou Y, Wang J. Experimental study of compressed air energy storage system with thermal energy storage. Energy 2016;103:182-91.

[29] Cheayb M, Gallego M, Tazerout M, Poncet S. Modelling and experimental validation of a small-scale trigenerative compressed air energy storage system. Applied Energy 2019;239:1371-84.

[30] Energy in buildings. Ministry of Ecological Transition. https://www.ecologiquesolidaire.gouv.fr/energie-dans-batiments; 2016 (accessed 14 October 2019).

[31] Green tech media. LightSail energy storage and the failure of the founder narrative, https://www.greentechmedia.com/squared/letter-from-sand-hill-road/lightsail-energy-storageand-the-failure-of-the-founder-narrative; 2003 [accessed 13 March 2003].

[32] Chicco G, Mancarella P. Assessment of the greenhouse gas emissions from cogenerationand trigeneration systems. Part I: Models and indicators. Energy 2008;33:410-17. 


\section{Appendix}

\section{Charge phase:}

Polytropic compression means: $P v^{n}=C t e=P_{\text {in }} v_{\text {in }}{ }^{n}=P_{\text {out }} v_{\text {out }}{ }^{n}$

$$
\begin{gathered}
w_{c, i}=\int_{P_{\text {in }}}^{P_{\text {out }}} v \mathrm{~d} p=\int_{P_{\text {in }}}^{P_{\text {out }}} \frac{P_{\text {in }}^{1 / n}}{P^{1 / n}} v_{\text {in }} d P=P_{\text {in }}^{1 / n} v_{\text {in }} \int_{P_{\text {in }}}^{P_{\text {out }}} \frac{d P}{P^{1 / n}} \\
w_{c, i}=\int_{P_{\text {in }}}^{P_{\text {out }}} v \mathrm{~d} p=P_{\text {in }}^{1 / n} v_{\text {in }}\left[\frac{P^{n-1 / n}}{n-1 / n}\right]_{P_{\text {in }}}^{P_{\text {out }}}=\frac{k}{k-1} P_{\text {in }}^{1 / k} v_{\text {in }}\left[P_{\text {out }}^{n-1 / n}-P_{\text {in }}^{n-1 / n}\right] \\
w_{c, i}=\int_{P_{\text {in }}}^{P_{\text {out }}} v \mathrm{~d} p=\frac{n}{n-1} P_{\text {in }}^{1 / n} v_{\text {in }} P_{\text {in }}^{n-1 / n}\left[\frac{P_{\text {out }}^{n-1 / n}}{P_{\text {in }}^{n-1 / n}}-1\right] \\
w_{c, i}=\int_{P_{\text {in }}}^{P_{\text {out }}} v \mathrm{~d} p=\frac{n}{n-1} P_{\text {in }} v_{\text {in }}\left[\frac{P_{\text {out }}^{n-1 / n}}{P_{\text {in }}^{n-1 / n}}-1\right] \\
w_{c, i}=\int_{P_{\text {in }}}^{P_{\text {out }}} v \mathrm{~d} p=\left(\frac{n}{n-1} R T_{\text {in }, c, i}\left[\beta_{c}(t)^{\frac{n-1}{n}}-1\right]\right) \frac{1}{\eta_{\text {pol }}}
\end{gathered}
$$

And using Poisson's law:

$$
\begin{gathered}
P_{\text {in }} v_{\text {in }}^{n}=P_{\text {out }} v_{\text {out }}^{n} \\
P_{\text {in }}\left(\frac{m R T_{\text {in }}}{P_{\text {in }}}\right)_{\text {in }}^{n}=P_{\text {out }}\left(\frac{m R T_{\text {out }}}{P_{\text {out }}}\right)_{\text {out }}^{n} \\
P_{\text {in }}^{1-n} T_{1}^{n}=P_{\text {out }}^{1-n} T_{\text {out }}^{n} \\
T_{\text {out }, c, i}=T_{\text {in }, c, i} \beta_{c}(t)^{\frac{n-1}{n}}
\end{gathered}
$$

\section{Storage phase:}

- Introducing air into the reservoir from compressors:

$$
\begin{gathered}
\mathrm{d}(m u)=+\dot{m}_{c} h_{i n} \mathrm{~d} t=h_{i n} \mathrm{~d} m \\
m \mathrm{~d} u+u \mathrm{~d} m=\left(u_{i n}+\left(\frac{P}{\rho}\right)_{i n}\right) \mathrm{d} m \\
m \mathrm{~d} u=\left(u_{i n}-u+\left(\frac{P}{\rho}\right)_{i n}\right) \mathrm{d} m=\left(c_{v} T_{\text {in,res }}-c_{v} T_{\text {res }}+r T_{\text {in,res }}\right) \mathrm{d} m \\
m c_{v} \mathrm{~d} T=\left(c_{v}\left(T_{\text {in,res }}-T_{\text {res }}\right)+r T_{\text {in,res }}\right) \mathrm{d} m
\end{gathered}
$$




$$
\begin{gathered}
m c_{v} \mathrm{~d} T=\left(c_{p} T_{\text {in,res }}-c_{v} T_{\text {res }}\right) \mathrm{d} m \\
\frac{c_{v} \mathrm{~d} T}{\left(c_{p} T_{\text {in,res }}-c_{v} T_{\text {res }}\right)}=\frac{\mathrm{d} m}{m} \\
\frac{\mathrm{d} T}{\left(\gamma T_{\text {in,res }}-T_{\text {res }}\right)}=\frac{\mathrm{d} m}{m}
\end{gathered}
$$

Fixing $x=\left(\gamma T_{\text {in,res }}-T_{r e s}\right)$ and $d x=-\mathrm{d} T$

$$
-\frac{\mathrm{d} x}{x}=\frac{\mathrm{d} m}{m}
$$

Integrating equation (17) between $\mathrm{j}$ and $\mathrm{j}+1$ :

$$
\begin{gathered}
\frac{\left(\gamma T_{i n, r e s}-T_{r e s}\right)_{j}}{\left(\gamma T_{i n, r e s}-T_{r e s}\right)_{j+1}}=\frac{m_{j+1}}{m_{j}} \\
\left(T_{r e s}\right)_{j+1}=\left(\gamma T_{i n, r e s}\right)_{j+1}-\frac{m_{j}}{m_{j+1}}\left(\gamma T_{\text {in,res }}-T_{r e s}\right)_{j}
\end{gathered}
$$

The ideal gas equation is used to calculate the increase of reservoir pressure at each time step (or the pressure decrease for air releasing phase):

$$
\left(P_{\text {res }}\right)_{j+1}=\frac{m_{j+1}\left(T_{r e s}\right)_{j+1} R}{V_{\text {res }}}
$$

With:

$$
m_{j+1}=\dot{m}_{c} \Delta t+m_{j}
$$

$\dot{m}_{c}$ is the air mass flow introduced the air reservoir a time step $\mathrm{j}$ and $m_{j}$ is the reservoir air mass equal to $\frac{\left(P_{\text {res }}\right)_{j} v_{\text {res }}}{R\left(T_{\text {res }}\right)_{j}}$.

- Releasing air from the reservoir into turbines:

Air leaving the high pressure reservoir process is described with the equations (22-28):

$$
\begin{gathered}
\mathrm{d}(m u)=-\dot{m}_{t} h_{\text {out }} d t=+h_{\text {out }} \mathrm{d} m \\
\mathrm{~d} u+u \mathrm{~d} m=\left(u_{\text {out }}+\left(\frac{P}{\rho}\right)_{\text {out }}\right) \mathrm{d} m \\
m \mathrm{~d} u=\left(u_{\text {out }}-u+\left(\frac{P}{\rho}\right)_{\text {out }}\right) \mathrm{d} m=\left(c_{v} T_{\text {out }, \text { res }}-c_{v} T_{\text {res }}+r T_{\text {out }, \text { res }}\right) \mathrm{d} m
\end{gathered}
$$




$$
\begin{gathered}
m c_{v} \mathrm{~d} T=\left(\left(c_{v}+r\right) T_{\text {out }, \text { res }}-c_{v} T_{\text {res }}\right) \mathrm{d} m \\
\frac{c_{v} \mathrm{~d} T}{\left(c_{p} T_{\text {out }, \text { res }}-c_{v} T_{\text {res }}\right)}=\frac{\mathrm{d} m}{m}
\end{gathered}
$$

In this case, $T_{\text {out }, \text { res }}=T_{\text {res }}$ and equation (26) can be simplified:

$$
\begin{gathered}
\frac{\mathrm{d} T}{T_{r e s}}=(\gamma-1) \frac{\mathrm{d} m}{m} \\
\frac{\left(T_{r e s}\right)_{j+1}}{\left(T_{r e s}\right)_{j}}=\left(\frac{m_{j+1}}{m_{j}}\right)^{\gamma-1}
\end{gathered}
$$

\section{Discharge phase:}

Polytropic expansion : $P v^{k}=C t e=P_{\text {in }} v_{\text {in }}{ }^{k}=P_{\text {out }} v_{\text {out }}{ }^{k}$

$$
\begin{gathered}
w_{t, i}=\int_{P_{\text {in }}}^{P_{\text {out }}} v \mathrm{~d} p=\int_{P_{\text {in }}}^{P_{\text {out }}} \frac{P_{\text {in }}^{1 / n}}{P^{1 / n}} v_{\text {in }} d P=P_{\text {in }}^{1 / n} v_{\text {in }} \int_{P_{\text {in }}}^{P_{\text {out }}} \frac{d P}{P^{1 / n}} \\
w_{t, i}=\int_{P_{\text {in }}}^{P_{\text {out }}} v \mathrm{~d} p=P_{\text {in }}^{1 / n} v_{\text {in }}\left[\frac{P^{n-1 / n}}{n-1 / n}\right]_{P_{\text {in }}}^{P_{\text {out }}}=\frac{n}{n-1} P_{\text {in }}^{1 / n} v_{\text {in }}\left[P_{\text {out }}^{n-1 / n}-P_{\text {in }}^{n-1 / n}\right] \\
w_{t, i}=\int_{P_{\text {in }}}^{P_{\text {out }}} v \mathrm{~d} p=\frac{n}{n-1} P_{\text {in }}^{1 / n} v_{\text {in }} P_{\text {in }}^{n-1 / n}\left[\frac{P_{\text {out }}^{n-1 / n}}{P_{\text {in }}^{n-1 / n}}-1\right] \\
w_{t, i}=\int_{P_{\text {in }}}^{P_{\text {out }}} v \mathrm{~d} p=\frac{n}{n-1} P_{\text {in }} v_{\text {in }}\left[\frac{P_{\text {out }}^{n-1 / n}}{P_{\text {in }}^{n-1 / n}}-1\right] \\
w_{t, i}=\int_{P_{\text {in }}}^{P_{\text {out }}} v \mathrm{~d} p=\left(\frac{n}{n-1} R T_{\text {in }, t, i}\left[\beta_{t}(t)^{\frac{n-1}{n}}-1\right]\right) \frac{1}{\eta_{\text {pol }}}
\end{gathered}
$$

And using Poisson's law:

$$
\begin{gathered}
P_{\text {in }} v_{\text {in }}^{n}=P_{\text {out }} v_{\text {out }}^{n} \\
P_{\text {in }}\left(\frac{R T_{\text {in }}}{P_{\text {in }}}\right)_{\text {in }}^{n}=P_{\text {out }}\left(\frac{R T_{\text {out }}}{P_{\text {out }}}\right)_{\text {out }}^{n} \\
P_{\text {in }}^{1-n} T_{1}^{n}=P_{\text {out }}^{1-n} T_{\text {out }}^{n} \\
T_{\text {out }, t, i}=T_{\text {in }, t, i} \beta_{t}(t)^{\frac{n-1}{n}}
\end{gathered}
$$

